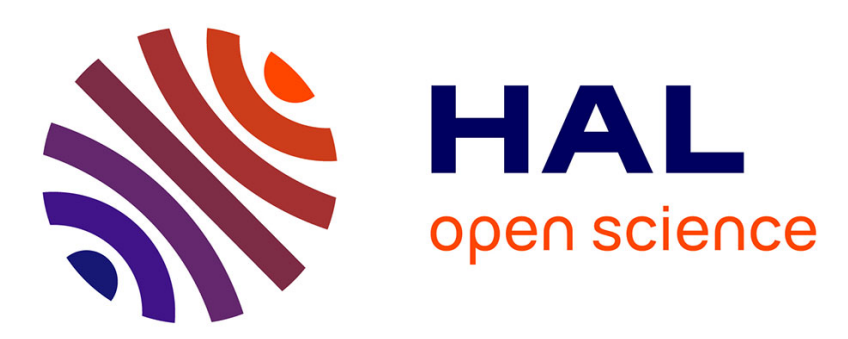

\title{
Considering human resource constraints for real joint production and maintenance schedules
}

S. Bouzidi-Hassini, F. Benbouzid-Si Tayeb, François Marmier, M. Rabahi

\section{To cite this version:}

S. Bouzidi-Hassini, F. Benbouzid-Si Tayeb, François Marmier, M. Rabahi. Considering human resource constraints for real joint production and maintenance schedules. Computers \& Industrial Engineering, 2015, 90, pp.197-211. 10.1016/j.cie.2015.08.013 . hal-01591962

\section{HAL Id: hal-01591962 \\ https://hal.science/hal-01591962}

Submitted on 7 Nov 2018

HAL is a multi-disciplinary open access archive for the deposit and dissemination of scientific research documents, whether they are published or not. The documents may come from teaching and research institutions in France or abroad, or from public or private research centers.
L'archive ouverte pluridisciplinaire HAL, est destinée au dépôt et à la diffusion de documents scientifiques de niveau recherche, publiés ou non, émanant des établissements d'enseignement et de recherche français ou étrangers, des laboratoires publics ou privés. 


\title{
Considering human resource constraints for real joint production and maintenance schedules
}

\author{
S. Bouzidi-Hassini ${ }^{\text {a,* }}$, F. Benbouzid-Si Tayeb ${ }^{\text {a }}$, F. Marmier ${ }^{\text {b,c }}$, M. Rabahi ${ }^{\text {a }}$ \\ ${ }^{a}$ Laboratoire des Méthodes de Conception de Systèmes, Ecole nationale Supérieure d'Informatique (ESI), BP 68M, 16270 Oued-Smar, Alger, Algeria \\ ${ }^{\mathrm{b}}$ Toulouse University, Mines Albi, Centre Génie Industriel, 81000 Albi Cedex 09, France \\ ${ }^{\mathrm{c}}$ Strasbourg University, BETA, 61 avenue de la Forêt Noire, 67085 Strasbourg Cedex, France
}

\section{A B S T R A C T}

This study deals with the problem of scheduling jobs and preventive maintenance (PM) activities in production workshops jointly in order to reduce failure occurrence. PM activities can be planned at fixed periods (time-based PM) or in response to a signal provided from a machine's captor after anomaly detection (condition-based PM). Maintenance activities' planning depends on different constraints like human resources, spare parts availability and past operating duration of the machine.

Proposed related works evaluate possible arrangements of both production and maintenance activities according to different criteria (makespan (Cmax: completion date of the last operation on the last machine), machine's failure risk, jobs' lateness, etc.). However, maintenance activities are frequently considered as production jobs. In fact, maintenance activities present different constraints and cannot be planned in the same manner as production ones. In addition to that, most of current works deal with the time-based maintenance planning even so condition-based maintenance is qualified as more realistic and more economic than the former.

This work discusses a new approach to integrate the scheduling of production and maintenance operations. Proposed approach takes explicitly into account human resources availability and skills when updating integrated production and maintenance schedules. It is based on multi-agent systems for modeling the production workshop.

Keywords:

Joint production and maintenance

scheduling

Preventive maintenance (condition-based

and time-based)

Human resource constraints

Multi-agent systems

Fuzzy estimation

\section{Introduction}

Production scheduling is concerned with allocating limited machines to a set of jobs along with certain objective functions that should to be optimized, i.e., in order to meet the deadlines by minimizing the sum of tardiness or makespan. According to the configuration of the workshop (single workstation, multiple workstations, flow-shop, job-shop, open-shop), some critical objectives should be optimized and certain types of constraints must be taken into account (preemption, setups, etc.) (Cox \& Blackstone, 1991).

Production workshops, by their nature, are subject to events (expected or not) such as arrival of new tasks, machine breakdowns, and defection of a human intervener. Also, production or maintenance tasks processing time cannot be estimated exactly

\footnotetext{
* Corresponding author.

E-mail addresses: s_hassini@esi.dz (S. Bouzidi-Hassini), f_sitayeb@esi.dz (F. Benbouzid-Si Tayeb), francois.marmier@mines-albi.fr (F. Marmier), m_rabahi@ esi.dz (M. Rabahi).
}

because it depends on many factors like machines' operating condition, used raw materials, and human resources competence. Consequently, deterministic solutions are frequently inadequate. Such solutions suppose that all relevant problem data are known precisely and unchanging. This assumption is far from the reality of production workshops.

It is important that used data accurately represent the environment in order to obtain realistic solutions. Recently, scheduling under uncertainties is proposed to address the shortcomings of deterministic scheduling. Dubois and Prade (1985) identify two types of data imperfection: imprecision and uncertainty. A data is imprecise if its value cannot be given exactly. It is uncertain whether there is a doubt concerning its validity. Generally, data imperfection is designed by the word "uncertainty" and no distinction is made for its two types. Four uncertainties models can be distinguished (Billaut, Moukrim, \& Sanlaville, 2005): stochastic models (Shakhlevich \& Strusevich, 2005), fuzzy logic based models (Dumitru \& Luban, 1982), interval models (Matsveichuk, Sotskov, Egorova, \& Lai, 2009) and scenario models (Aloulou \& Croce, 2008). Fuzzy logic is widely used in the literature to model 
scheduling data imprecision as it allows representing and treating approximate or uncertain knowledge (Chanas \& Kasperski, 2001; Marmier, Varnier, \& Zerhouni, 2009; Petrovic, Petrovic, \& Burke, 2011).

In recent years, there have been tremendous efforts to solve scheduling problems under uncertainties because many researchers have identified deterministic scheduling insufficiencies. For solving the scheduling problem, two phases where uncertainties can be treated are distinguished: the proactive phase (offline) and the reactive phase (in-line). Several classifications of resolution methods exist in the literature and this according to the developed phase. We hold the one of Chaabi (2010) which distinguishes three types of approaches: proactive approaches, reactive approaches and hybrid approaches which include the two phases.

In order to avoid machines' failure, maintenance activities are planned periodically. This maintenance policy is called preventive maintenance (PM). PM is defined as the activity undertaken while the machine is satisfactorily operating, to reduce or eliminate the accumulated deterioration (Sim \& Endrenyi, 1988). Generally, there exist two types of preventive maintenance schemes, i.e. condition-based (CBM) and time-based preventive maintenance (TBM) (Legat, Zaludova, Cervenka, \& Jurca, 1996). For CBM, the action taken depends on the state of the system. It could be no action, or minimal maintenance to recover the system to the previous stage of degradation, or major maintenance to bring the system to "as good as new state". It is based on the condition monitoring process, where signals are monitored using certain types of sensor or other appropriate indicators (Campos, 2009). For TBM, the preventive maintenance is carried out at pre-determined time intervals to bring the system to "as good as new state" (Vaurio, 1997). The periodicity $T$ of TBM activities can vary in a tolerance interval noted $\left[T_{\min }, T_{\max }\right]$ (Benbouzid, Varnier, \& Zerhouni, 2003). This interval gives some flexibility to plan TBM activities while respecting production constraints, disturbing the least possible the production schedule, and respecting the maintenance equipment periodicity.

Production and maintenance have been treated for a long time as two separate functions (Altuger \& Chassapis, 2009; Kulscar \& Forrai, 2009; Pereira, Lapa, Mol, \& da Luz, 2010; Sawik, 2005); nowadays, and because of the interdependence between these functions, there is a great interest to develop optimization models that consider the integration of the two of them (Benmansour, Allaoui, Artiba, Iassinovski, \& Pellerin, 2011; Benbouzid-Sitayeb, Guelbi, Bessadi, Varnier, \& Zerhouni, 2011).

Maintenance integration can be sequential or total (Lee \& Chen, 2000). A sequential integration consists of two steps: first, scheduling the production jobs then inserting maintenance operations, taking the production schedule as a mandatory constraint of machines unavailability in the resolution of the problem. On the other hand, a total integration consists of simultaneously scheduling both production and maintenance operations. Such policy limits conflict risks, and thus makes it possible to optimize a joint objective function (Brandolese, Fransi, \& Pozzeti, 1996; Sloan \& Shanthikumar, 2000).

By reviewing the literature, no work focuses on integrated production and maintenance scheduling with the CBM strategy. Only TBM strategy is considered despite the fact that CBM strategy has been widely recommended because it reduces unnecessary maintenances and related costs (Gupta \& Lawsirirat, 2006) by planning only needed maintenance activities. Rosmaini and Shahrul (2012) present an overview of the TBM and CBM policies. They admit that the CBM policy is more preferred because it is simpler than the TBM as long as the former is based on the optimization approach. They consider that CBM application is more realistic because $99 \%$ of equipment failures are preceded by certain signs conditions or indications that inform such a failure was going to occur. The choice of the maintenance policy depends on the maintenance activity itself. TBM policy application seems trivial for simply and shortly activities like cleaning and inspection. However for activities with important processing time and cost, like a component replacement, the CBM is more interesting. So it can be necessary to consider both policies for machines maintenance. The CBM monitoring process consists of two phases: analysis and prognostic. The analysis phase interprets received signals in order to determine the failure nature. Whereas the prognostic consists on determining the remaining useful life of the equipment (RUL) of the equipment according to analysis phase results. All works in CBM answer to the question "when it is necessary to plan a maintenance activity?". They try to find the most significant indicators that announce the failure occurrence. Their objective is to precisely predict the RUL. However, they do not treat the problem of where inserting the maintenance activity in the current production plan.

When a CBM activity needs to be planned in any running schedule, two alternatives may be adopted to update this latter: generating a new schedule or altering the predictive schedule to adapt it to new conditions. As (Seguy, Noyes, \& Clermont, 2010), we consider that the first alternative might in principle be better for maintaining optimal solutions, but these solutions require prohibitive computation times. Moreover, frequent schedule regeneration can result in instability and lack of continuity in detailed plant schedules, leading to additional production and maintenance costs attributable to what has been termed "shop floor nervousness" (Dorn, Kerr, \& Thalhammer, 1993). Things will be more complicated when human resources are involved which is the case of maintenance activities. These latter will be disturbed by seeing their schedules change frequently. Therefore, it is more reasonable to adapt schedules partially. Given that maintenance activities, involve human resources with different competences and availability, the objective of updating obsolete schedules should not only be the generation of optimal schedules, but finding schedules that by one side maintain the production goals and satisfy the scheduling constraints and, on the other hand, are able to be easily adapted to human resources availability (Martorell, Villamizar, Carlos, \& Sanchez, 2010).

Faced with an unexpected event such as CBM activity, the decision must be made quickly in order to not disturb production process. This propriety is called "reactivity". The management of production workshop floors should be based on solutions that support reactivity and autonomy in decision making. A top-down centralized system for decision making can cause rigidity and limit problem solving ability in real world (Jones \& Rabelo, 1998; Shen, Wang, \& Hao, 2006), although centralization can provide a consistent global view of the state of the system (Ouelhadj \& Petrovic, 2009). A distributed approach to control and scheduling attempts to address the inflexibility of hierarchical systems. Multi Agent Systems (MAS) address these needs; they are defined as a collection of autonomous entities called Agents that alone or in cooperation with other ones aim to achieve a goal. MAS have been widely applied in scheduling problems (Li, Zhang, Gao, Li, \& Shao, 2010; Owliya, Saadat, Goharian, \& Anane, 2010). Agents may represent any actor like machines (Kouiss, Pierreval, \& Mebarki, 1997; Owliya et al., 2010) jobs or operations (Li et al., 2010) and human interveners (Sabar, Montreuil, \& Frayret, 2009). Agent proprieties such as decision autonomy, reaction and collaboration make their use profitable in the case of dynamic environments where events may appear like machines breakdown or arrival of new tasks. Agents negotiate to get an agreement on the best production and maintenance activities' arrangement while satisfying the scheduling problem constraints. Khelifati and Benbouzid-Sitayeb (2011) presents a multi-agent approach for scheduling jobs and maintenance operations in a flowshop sequencing problem. They propose an approach for production, TBM and CM scheduling. Firstly, they 
propose an integrated production and TBM scheduling then, when the breakdown appears (arrival of a CM activity), affected machine agent proceed by rescheduling maintenance and production tasks as in Li et al. (2010).

In recent works, human resources are exploited separately in production (Guyon, Lemaire, Pinson, \& Rivreau, 2010; Sabar et al., 2009) and maintenance planning (De Snoo, Van Wezel, Wortmann, \& Gaalman, 2011; Marmier et al., 2009) and not in integrated production and maintenance scheduling. Sabar et al. (2009) present a MAS approach for personnel scheduling problems in the context of a paced multi-product assembly center. Its purpose is to elaborate daily assignment of employees to workstations in order to minimize simultaneously the operational costs and personnel dissatisfactions. Guyon et al. (2010) investigate the integration of the employee timetabling and production scheduling problems. At the first level, it manages a classical employee timetabling problem. At the second level, it aims at supplying a feasible production schedule for a set of interruptible tasks with qualification requirements and time-windows. Instead of hierarchically solving these two problems as in the current practice, it tries to integrate them and propose two exact methods to solve the resulting problem. De Snoo et al. (2011) present an extension for maintenance planning by inserting the human and material resources. The work addresses the effect of these constraints on the optimization of maintenance according to the $\mathrm{RAM}+\mathrm{C}$ criteria (Reliability, Availability, Maintainability and Cost). Marmier et al. (2009) propose multi-criteria approach for planning TBM preventive and curative maintenance activities with consideration of human resources skills because the competence level influences the task processing time. We admit that it is more interesting to consider human resources for maintenance activities because they are mostly manual activities where the competence level of human resources influences on their processing time. The role of human resources in production process is usually controlling the process runs smoothly. Hence, processing time of production jobs depends generally on machine states and raw materials but not on human resources that control the production process.

To the best of our knowledge, there no previous study on integrating production and maintenance scheduling with the CBM strategy. In this way, in this paper, we propose an integrated scheduling model in two phases: Firstly, we present a one-machine resolution in which we explain how the machine subject to maintenance will proceed to update its plan when a CBM activity has to be inserted after need detection. We take into account the human resources skill and availability to affect the activity to the best maintenance intervener. Then we propose a multi-machine resolution. In order to balance the trade-offs between production scheduling and PM planning, we aim to simultaneously optimize total tardiness of production tasks and machine breakdown risk. According to the new CBM planning, we identify two decision strategies for managing maintenance: (1) maintenance oriented strategy (planning the activity when the anomaly appears), and (2) production oriented strategy (planning the activity as late as possible in order to disturb less possible the current plan). We propose a multi-agent architecture for the workshop in order to take advantage of reactivity, autonomous decision making and collaboration proprieties of agents. Moreover, we adopt a fuzzy estimation of used data so that they represent actually the real scheduling problem.

The rest of the paper is organized as follows: The problem description is provided in Section 2. Section 3 describes the proposed method. Section 4 is devoted to the computational experiments. Finally, Section 5 enumerates the method's advantages and presents some future researches.

\section{Jobs re-scheduling with machine maintenance and human resources constraints}

This study deals with the problem of updating an integrated production and maintenance schedules when a new CBM activity has to be planned on a given machine.

We consider a multi-machine workshop where each machine $M_{i}$ executes an integrated plan composed of production jobs and TBM activities. Machines operation is monitored throughout the production process using sensors. These latter are connected to a computer on which a decision-making software is running. The software compares recollected data with normal machines state and acts in case of malfunctioning.

We call "Subject Machine" (SM) the machine $M_{i}$ on which anomalies were detected. In order to avoid failure appearance and thus interrupt the production process, a new CBM activity $j$, noted $\mathrm{CBM}_{i j}$, has to be inserted in the $M_{i}$ current schedule.

The RUL (remaining useful life) is the useful life left on an asset at a particular time of operation. Its estimation is essential to CBM prognostics and health management. It is an estimated breakdown date before which it is necessary to intervene. The RUL is therefore considered as the deadline for CBM planification. It is estimated from available sources of information such as information obtained in condition and health monitoring (Si, Wang, Hu, \& Zhou, 2011). Despite that, its estimation is most often approximate and inexact.

After starting production plan execution, collected data on a machine $M_{i}$ sensors indicate a malfunction (point "P" - Fig. 1a) and thereby advert the appearance of a failure (point " $F$ " Fig. 1a). The two points "P" and "F" are sometimes referred to as the leading indicators to failure of an asset or the failure development period. The pattern of the P-F Interval is reflected on a P-F Curve (Fig. 1a) and is used to express the probability of failure of an asset (Huang, Jiang, Chen, \& Chen, 2014).

After its identification at $t_{1}$, necessary $\mathrm{CBM}_{i j}$ has to be planned in order to avoid failure. Ideally, $\mathrm{CBM}_{i j}$ is planned before $\mathrm{RUL}_{i}$ end i.e. inside the interval $\left[t_{1}, t_{f}\right]$. If $\mathrm{CBM}_{i j}$ is planned after $\mathrm{RUL}_{i}$, breakdowns are likely to appear and consequently the machine would be unavailable. As $t_{f}\left(\mathrm{RUL}_{i}\right.$ end) is inexact, we suppose that it could vary between two values $\operatorname{DdlS}_{i}$ (Deadline Start) and $\operatorname{DdlE}_{i}$ (Deadline End) (Fig. 1a).

Each maintenance activity (TBM or CBM) requires a competence or a qualification for its execution. Processing time of maintenance activities depends on interveners' competence level. We suppose that each intervener according to its experience can estimate the time for executing maintenance activities. Moreover, as work started in the workshop, human resources that intervene in maintenance have already their planning. Consequently, competence and availability constraints have to be considered when planning the maintenance activity so as to propose realistic schedules.

The choice of maintenance planning date is difficult because production is underway. Interrupting the production process for maintenance could cause delays in delivery. In order to offer flexibility to deciders and to balance the trade-offs between risk of machine unavailability and production delays, we propose two strategies for managing machines' maintenance: (1) Maintenance Oriented Strategy (MOS) and (2) Production Oriented Strategy (POS) (Fig. 1b).

(1) When MOS is applied, the $\mathrm{CBM}_{i j}$ activity has to be planned rather than possible without waiting for reaching $t_{f}$ minimal value $\left(\mathrm{Ddll}_{i}\right)$, i.e. the $\mathrm{CBM}_{i j}$ activity has to be planned in the interval $\left[t_{1}, \mathrm{DdlS}_{i}\right]$.

(2) POS: In this strategy, a risk can be tolerated in order to do not disturb the production plan. $\mathrm{CBM}_{i j}$ activity is planned after DdlS $_{i}$, i.e. in the interval [Ddls $\left.{ }_{i}, \operatorname{Ddll}_{i}\right]$. 


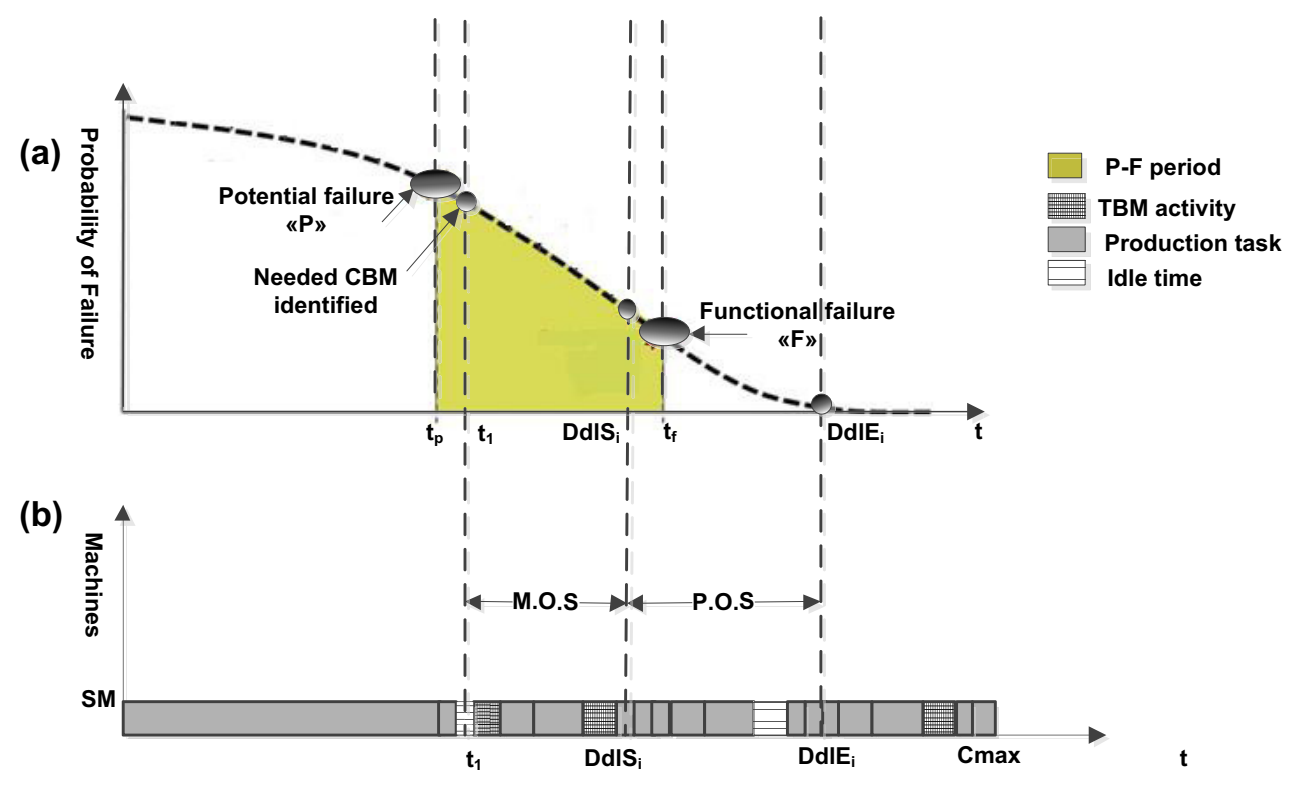

Fig. 1. P-F curve and maintenance strategies.

In following, we present production scheduling problem, preventive maintenance planning problem with human resource constraints and objective functions to optimize.

\subsection{Production scheduling problem}

There are a set $M=\left\{M_{1}, M_{2}, \ldots M_{m 0}\right\}$ of $m_{0}$ machines and a set $P=\left\{P_{1}, P_{2} \ldots P_{m 1}\right\}$ of $m_{1}$ production jobs scheduled on $M$. Each production job $P_{k}$ on a machine $M_{i}$ is characterized by a release date $r_{i k}$, an execution date $t_{i k}$, a processing time $p_{i k}$, a completion date $c_{i k}$ and a due date $d_{i k}$.

The processing times are fixed and non-negative. Further, assumptions are that each job can be processed on only one machine at a time, the operations are non preemptable, and no set-up time is considered or it can be integrated in the processing time of each operation.

\subsection{Preventive maintenance planning problem with human resource constraints}

Each $\mathrm{TBM}_{i\{}\left\{l=1, \ldots m_{2}\right\}$ planned on a machine $i$ is characterized by an execution time $t_{i l}^{\prime}$ and a completion time $c_{i l}^{\prime}$. CBM activities are planned just after need detection, so they are associated with an event that has to be handled on the workshop. Each $\mathrm{CBM}_{i j}\left\{j=1, \ldots m_{3}\right\}$ activity is characterized by $p_{i j}^{\prime}$ its processing time, $c r_{i j}$ a competence or a qualification required from interveners for its execution and a deadline $R U L_{i}$ that should be respected when planning $\mathrm{CBM}_{i j}$ in order to keep the machine in operation. Actually $p_{i j}^{\prime}$ and $\mathrm{RUL}_{i}$ could not be known exactly. That is why we adopt an approximate estimation by using fuzzy sets. $p_{i j}^{\prime}$ and $\mathrm{RUL}_{i}$ are modeled by the fuzzy sets $\widetilde{p_{i j}^{\prime}}$ and $\widetilde{R U L}_{i}$ with a triangular membership function defined by the triplet $\left(v_{f}^{1}, v_{f}^{2}, v_{f}^{3}\right)$ representing respectively (minimal, most probable and maximal value) of $f$ with $f=\left\{p_{i j}^{\prime}\right.$, RUL $L_{i}$ ) (Fig. 2a).

The choice of a triangular function is justified by the fact that CBM processing time or RUL are generally defined by certain estimation; this estimation is represented by point $v_{f}^{2}$. If the estimation was not as expected (lower or upper value than $v_{f}^{2}$ ),

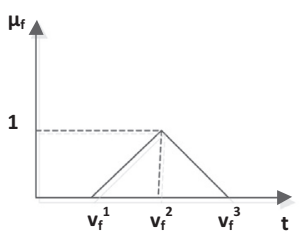

(a)

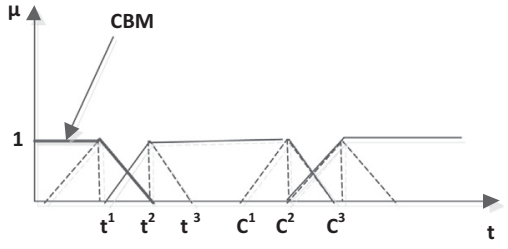

(b)
Fig. 2. Fuzzy modeling of processing time, RUL and task execution intervals.

the value will be represented by a point within $\left[v_{f}^{1}, v_{f}^{2}\right]$ or within $\left[v_{f}^{2}, v_{f}^{3}\right]$.

The fuzziness of $\mathrm{CBM}_{i j}$ processing time $\widetilde{p_{i j}^{\prime}}$ has an impact on its completion time $\left(c_{i j}^{\prime}\right)$ and the execution interval ${ }^{1}$ bounds of tasks that succeed it. Tasks execution interval is also fuzzy with a trapezoidal membership function (Fig. 2b). Regarding the deadline $\widetilde{R U L}_{i}$, its fuzziness will have an impact only on decision of when planning the $\mathrm{CBM}_{i j}$ (see Section 3).

The maintenance service involves human interveners with different competences and availability. Indeed, competence level of human resources has a direct effect on processing time of activities they execute. Regarding availability, this constraint affects the feasibility of maintenance planning. Consequently, each human resource $\mathrm{HR}_{m}\left\{m=1, \ldots, m_{4}\right\}$ is characterized by $\mathrm{CR}_{m}=\left\{\mathrm{cr}_{m 1}, \mathrm{cr}_{m 2}, \ldots\right\}$ the set of competences that allow $\mathrm{HR}_{m}$ executing maintenance activities, a set of intervals $\mathrm{IA}_{m}=\left\{\mathrm{IA}_{m 1}, \mathrm{IA}_{m 2}, \ldots\right\}$ representing his availability. With $\mathrm{IA}_{m n}=\left[\mathrm{IAmin}_{m n}, \mathrm{IAmax}_{m n}\right]$ and $p_{m p}^{\prime \prime}$ processing time that proposes for executing a maintenance activity $p$ (TBM or CBM) on machine $M_{i}$. We admit that each $\mathrm{HR}_{\mathrm{m}}$ according to its experience can estimate the approximate $p_{m p}^{\prime \prime}$ and express it in a fuzzy form $\widetilde{p_{m p}^{\prime \prime}}$ for which we propose also a triangular membership.

\subsection{Objective functions}

The goal of the proposed approach is to insert a new CBM into an existing integrated schedule, i.e. taking into account human

\footnotetext{
${ }^{1}$ Execution interval $=[$ starting date, completion date $]$.
} 
resources availability and competence. The aim is to disturb the current plan less possible while minimizing the risk of machine's breakdown.

Disturbing at least the current schedule means that execution intervals of current production and TBM activities have to be changed minimally. We admit that TBM activities will not be changed because they have been planned taking into account several constraints like human resource constraints and tools availability. Our objective is to propose only a partial rescheduling instead of a total one. Execution intervals of production jobs can be modified because their planning depends only on production machines that exist on the workshop. The production objective is then to minimize the average tardiness $\left(\widetilde{f_{1}}\right)$ of production jobs (Eq. (1)). Tardiness $\widetilde{\left.T_{i k}\right)}$ of a job $k$ executed on a machine $i$ is calculated according to (Eq. (2))

$\widetilde{f_{1}}=1 / m 1 \sum_{i=0}^{m 1} \widetilde{T_{i k}}$

$\widetilde{T_{i k}}=\operatorname{Max}\left(0,\left(\left(\widetilde{c_{i k}}\right)-d_{i k}\right)\right)$

The functional failure of the SM depends on the date $t_{i j}^{\prime}$ where $\mathrm{CBM}_{i j}$ will be planned on it after signal reception at $t_{0}$. We call the period between $t_{0}$ and the $t_{i j}^{\prime} C B M$ tardiness (Eq. (3)). The risk of failure increases with maintenance tardiness increase.

$f_{2}=\operatorname{Max}\left(0,\left(t_{i j}^{\prime}-t_{0}\right)\right)$

In conclusion, the problem amounts to minimize the global objective function $\tilde{f}$ (Eq. (4)) which is defined as a weighted sum of average production tardiness $\widetilde{f_{1}}$ and CBM-tardiness $f_{2}$.

$\left\{\begin{array}{l}\tilde{f}=w_{1} \widetilde{f_{1}}+w_{2} f_{2} \\ w_{1}+w_{2}=1\end{array}\right.$

Weights $w_{1}$ and $w_{2}$ measure the respective effects of production tardiness and CBM tardiness in the global objective function $\tilde{f}$. Their values depend on the adopted strategy of maintenance: (1) when MOS is considered, the CBM tardiness is low. Therefore, we focus on minimizing production jobs tardiness by giving to $\widetilde{f_{1}}$ an important weight $\left(w_{1}>w_{2}\right)$; (2) whereas, in the case of POS, as the $\mathrm{CBM}_{i j}$ will be planned after Ddl $S_{i}$, the CBM tardiness will be significant. Thus, $f_{2}$ will have the most important weight.

\section{Resolution approach}

In this paper, we propose a two levels resolution approach: (1) the one-machine level; and (2) the multi-machine level. The onemachine level describes SM's behavior for inserting the new $\mathrm{CBM}_{i j}$ into its current schedule taking into account human resource constraints which are competence and availability. The schedule resulting from the one-machine resolution may affect schedules of SM's adjacent machines (upstream and downstream machines). In order to readjust their schedules, in the multi-machine level, the SM initiates a re-negotiation with upstream machines. Then it informs the downstream machines of the resulted schedule in order to update their local plans if lateness will be caused. In order to take advantage of SMA proprieties, we propose a multi-agent architecture for our system.

\subsection{Proposed MAS architecture}

Agents interact and collaborate to get an agreement on the final schedule. They communicate directly by message exchanging. We identify three agent types: Machine Agent, Maintenance Agent and Human Resource Agent.

(a) Machine Agent (MA) represents a machine. Its role is to control the execution of tasks on the machine it represents. There are three types of MA: (1) the Subject Machine Agent (SMA) that represents the SM, (2) the Upstream Machine Agent (UMA) which represents any machine situated before the MA and finally, (3) the Downstream Machine Agent (DMA) which represents at its turn any machine situated after SM.

(b) Maintenance Agent (MCA), its role is diagnosing machine breakdowns, identifying needed maintenance activities and estimating the RUL duration of the machine (prognostication).

(c) Human Resource Agent (HRA) represents a maintenance intervener. Its role is to construct its execution plan by negotiating intervention intervals with SMA by the intermediate of MCA.

Behaviors of proposed agents are illustrated in Figs. 3 and 4 and will be described in subsections thereinafter.

\subsection{One-machine resolution}

In this section, we describe the SMA's local resolution i.e. how the SMA proceeds for inserting CBM activity in the current plan. We propose a partial rescheduling where only production jobs order can be adjusted. It consists of seven stages: (1) initialization stage, (2) analysis stage, (3) call for intervention stage, (4) proposals formulation stage, (5) reception stage (6) scheduling and evaluation stage and finally (7) finalization stage. Figs. 3 and 4 illustrates respectively interaction and activity diagrams of involved agents.

\subsubsection{Initialization stage}

When the SMA receives signals from captors, it sends an analysis request to the MCA. The request is composed of signals code and information relevant to machines' state. Information allows MCA to determine the problem, suggestion of needed maintenance activity and estimation of RUL.

\subsubsection{Analysis stage}

In this stage, according to information sent by SMA, the MCA first identifies the problem as well as needed maintenance activity for correcting the anomaly and then estimates the $\mathrm{RUL}_{i}$ duration. This latter is fuzzy and is defined by three points [Ddls $s_{i}, t_{f}, \operatorname{DdlE}_{i}$ ] (Fig. 1a). Many interesting works could be adopted for implementing MCA (Bach, Althoff1, Newo, \& Stahl, 2011; Chebel-Morello, Haouchine, \& Zerhouni, 2009; Hanemann, 2006). Tobon-Mejia, Medjaher, Zerhouni, and Tripot (2011) propose a system for bearings RUL estimation based on the utilization of Mixture of Gaussians Hidden Markov Models (MoG-HMMs). The raw signals provided by the sensors are first processed to extract features, which permit to model the physical component and its degradation. The prognostic process is done in two phases: a learning phase and an evaluation phase. Once the learning phase is done, the generated model is exploited during the second phase, where the extracted features are continuously injected to the learned model to assess the current health state of the physical component and to estimate its RUL and the associated confidence.

\subsubsection{Call for intervention stage}

The MCA is involved with a database called "a referential" that contains all HRAs and their competences. Thus, it sends a call for proposals (CFP) to the interveners qualified to perform the activity. 


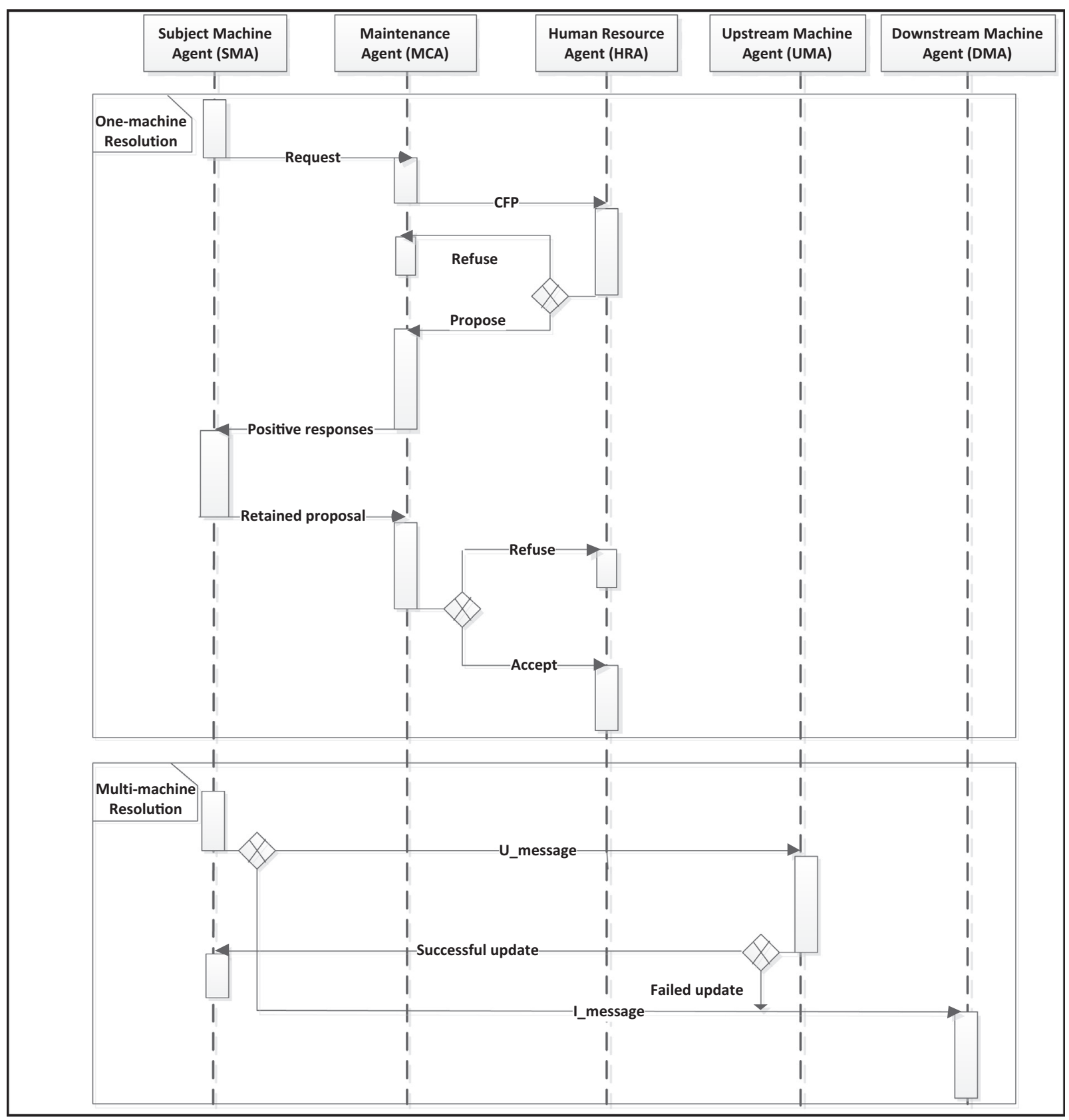

Fig. 3. Multi-agents interaction protocol.

The CFP is composed of the activity identifier $\mathrm{CBM}_{i j}$ and the preferred interval of intervention $I_{i j}$ that depends on chosen maintenance strategy $\left(I_{i j}=\left[t_{1}, \mathrm{DdlE}_{i}\right]\right.$ for MOS and $I_{i j}=\left[\mathrm{DdlE}_{i}, \mathrm{DdlE}_{i}\right]$ for POS).

\subsubsection{Proposal formulation stage}

Each contacted $\mathrm{HRA}_{m}$ checks its plan of intervention. According to its availability, it responses to the MCA's call. We suppose that each contacted $\mathrm{HRA}_{m}$ can have several intervals of availability, so it sends several proposals to the MCA. A proposal is composed of: the activity identifier $\mathrm{CBM}_{i j}$, a list of Availability intervals $\mathrm{AI}_{m}$ and a processing time $\widetilde{p_{j m}^{\prime \prime}}$ that it could take to execute the activity, $\widetilde{p_{j m}^{\prime \prime}}$ is defined by three points $\left[p_{j m 1}^{\prime \prime}, p_{j m 2}^{\prime \prime}, p_{j m 3}^{\prime \prime}\right]$. Algorithm 1 describes the behavior of each contacted HRA ${ }_{m}$.
Algorithm 1. $\mathrm{HRA}_{\mathrm{m}}$ Behavior.

Let $\widetilde{\mathrm{p}_{j m}^{\prime \prime}}$ the time proposed by $\mathrm{HRA}_{\mathrm{m}}$ for processing $\mathrm{CBM}_{i j}$ activity, [Imin $\mathrm{I}_{i j}, \operatorname{Imax}_{i j}$ ] the suggested interval of intervention proposed by the MCA and Prop_list the list of proposals.

Case1. When the $\mathrm{HRA}_{\mathrm{m}}$ receives a CFP it proceeds as follow:

Step1. It identifies the processing time $\widetilde{\mathrm{p}_{j m}^{\prime \prime}}$

Step2. From Imin $\operatorname{Im}_{i j}$ and while $\operatorname{Imax}_{i j}$ is not exceeded, for each availability interval with a length $>=p_{j m 3}^{\prime \prime}$, it inserts this interval into Prop_list

Step3. It sends the Prop_list to MCA. 


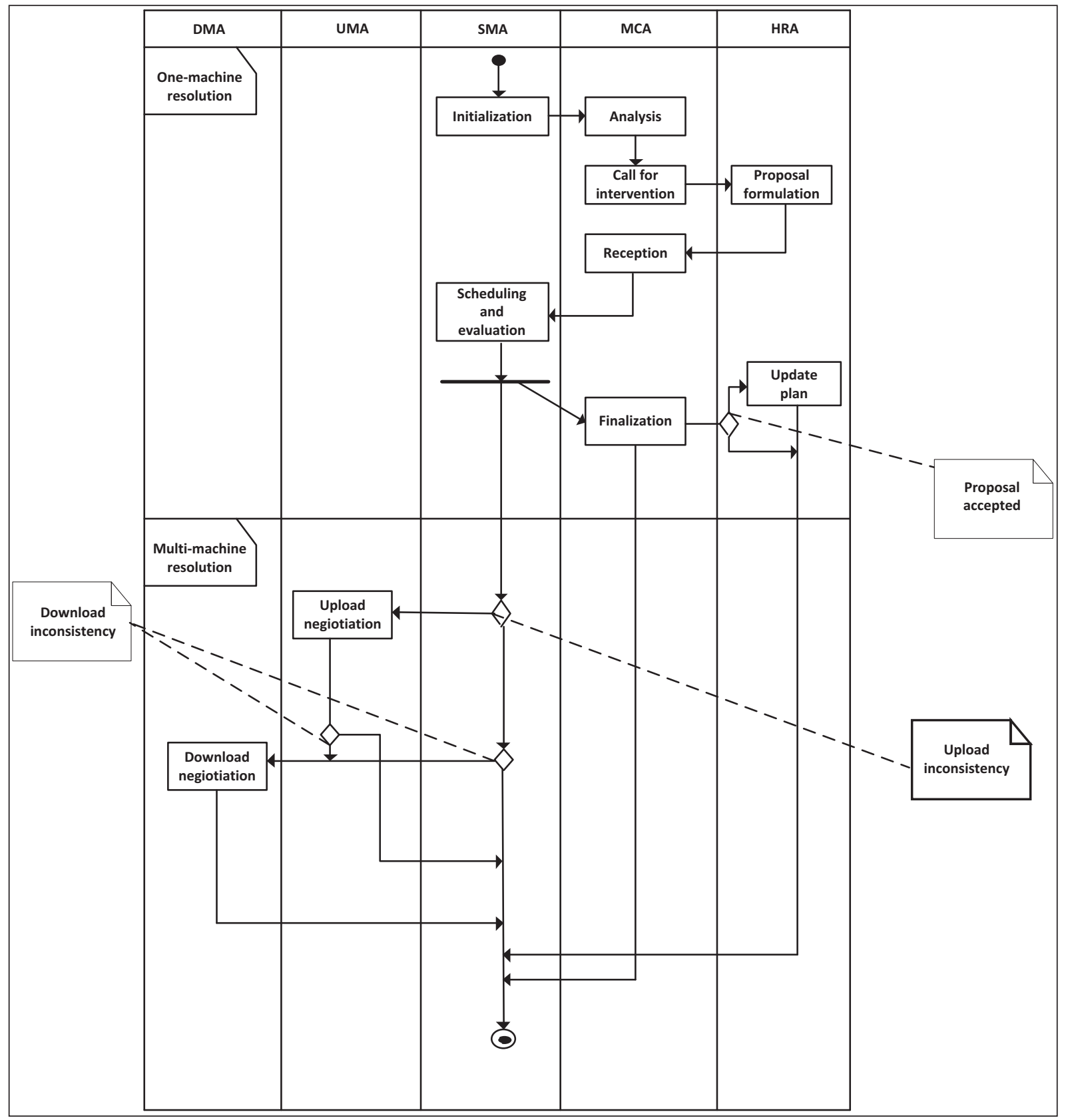

Fig. 4. Multi-agent activity diagram.

Case2. When the $\mathrm{HRA}_{\mathrm{m}}$ receives an intervention confirmation; it updates its plan and its availability

\subsubsection{Reception stage}

In this stage, MCA receives responses from contacted HRAs. It retains positive responses (acceptations) and transmits them to the SMA.

\subsubsection{Scheduling and evaluation stage}

The SMA proceeds by evaluating proposals in order to select the best one according to its objective. We define "a position" that is a date where we can insert the maintenance activity (see Fig. 6(0)). It is located between each completion time of a production job and starting date of the following TBM activity. The SMA selects first a maintenance strategy (maintenance or production oriented strategy), and then tries to insert $\mathrm{CBM}_{i j}$ in the most adapted position that fits the best with HRA availability intervals. If no proposal is done in a strategy intervention interval, the SMA moves to the other strategy. If despite this, no proposal fits with the new intervention interval, rescheduling is executed. In positive case, it schedules production jobs in order to optimize the production objective function $\left(\widetilde{f}_{1}\right)$ (Algorithm 2 ). Finally, it evaluates all resulting schedules (according to the objective function $\tilde{f}$ ) then selects the one that minimizes best $\tilde{f}$. 
Algorithm 2. The SMA behavior.

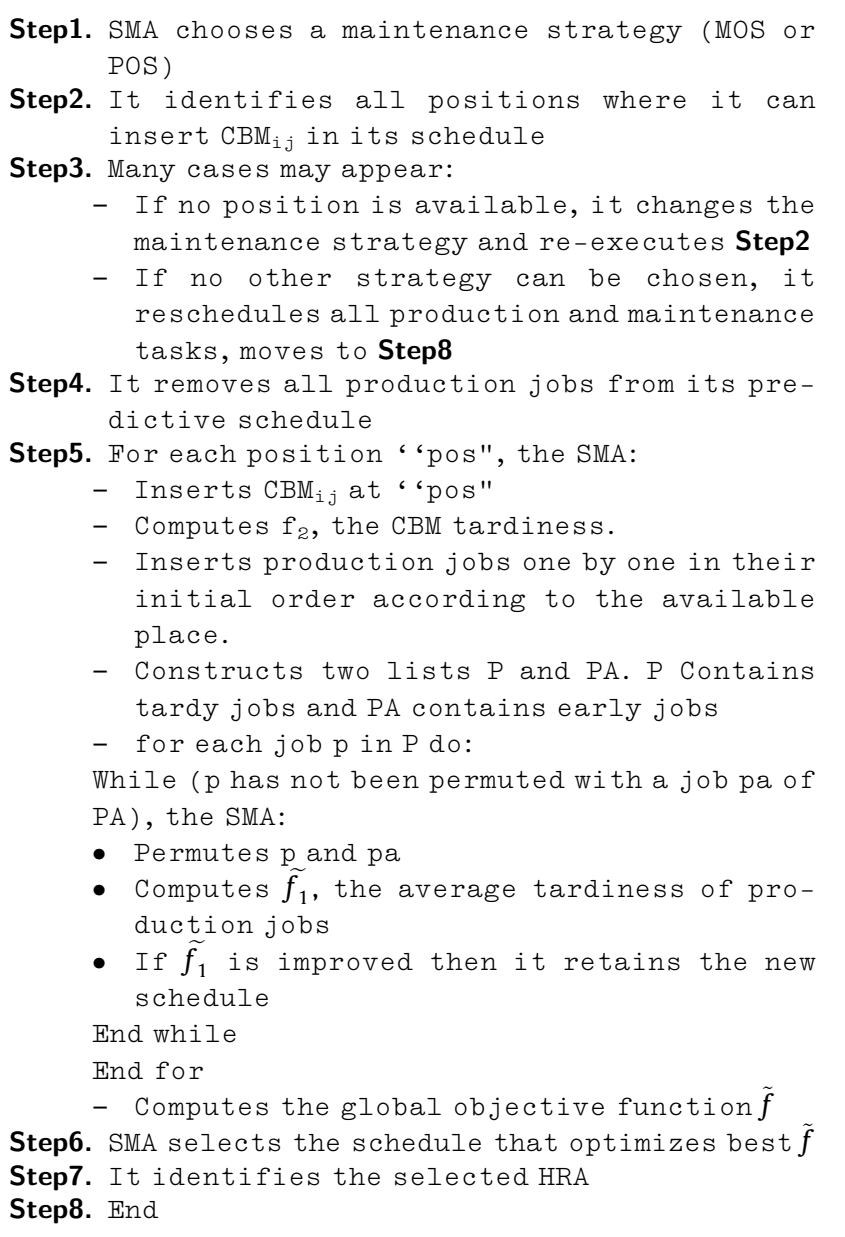

\subsubsection{Finalization stage}

After evaluation, the SMA sends its decision to the MCA that will inform after that the corresponding HRA of the decision by sending a confirmation proposal. Also a disconfirmation message will be sent to the rest of contacted HRAs. The selected HRA then updates its availability plan by inserting $\mathrm{CBM}_{i j}$ and notifies the correspondent real human resource by sending a message to him. He is informed that changes were brought to his schedule.

\subsubsection{Illustrative example}

We consider an SMA with a plan presented in Fig. 5. Table 1 summarizes all data relative to this plan tasks. Through this example, we will describe the proposed one-machine resolution.

(a) Initialization stage: We suppose that an anomaly has been detected during the execution of $P_{4}$ at $t_{8}$. While waiting for $P_{4}$ completion time, the SMA treats the signal. It sends an analysis request to the MCA.

(b) Analysis stage: We suppose that MCA identifies needed maintenance activity, potential interveners able to execute it and RUL $=[100,120,140]$. This stage takes 3 time units.

(c) Call for intervention stage: the MCA sends a call for proposal to identified HRAs. We suppose that it chooses a MOS for managing maintenance activities. Consequently, the suitable interval for intervention will be $[\mathrm{t} 11, \mathrm{t} 90]$

(d) Proposal formulation stage: We suppose that two interveners $H R A_{1}$ and $H R A_{2}$ proposed respectively $((4,7,9)$, [t20, t40]) and $((3,6,9)$, [t76,t105]) for processing time and availability interval.

(e) Evaluation stage: As the MOS is adopted, objective function weights $w_{1}$ and $w_{2}$ will be respectively 0.75 and 0.25 . SMA proceeds by evaluating the two proposals:

(e.1) $H R A_{1}$ proposal evaluation: According to its plan, the SMA has only the position t24 (Fig. 5(0)) where it can insert $\mathrm{CBM}_{i j}$ between t20 and t40. Consequently, $f_{2}=\operatorname{Max}(0,(24-8))=16$.

In order to build its new schedule, the SMA, removes, firstly, all production jobs from the current plan and leaves TBM activities (Fig. 6(1)). After that, it tries to add production jobs one by one according to their order in the predictive schedule i.e. $\mathrm{P}_{3}, \mathrm{P}_{2}$, and $\mathrm{P}_{1}$. SMA's scheduling can be summarized into two steps:

Step1: It schedules $P_{1}, P_{2}$ and $P_{\mathbf{3}}$ according to their order: First, it tries to insert $\mathrm{P}_{3}$ just after $\mathrm{CBM}_{i j}$ but it cannot because its processing time is bigger than the idle time between $\mathrm{CBM}_{i j}$ and $\mathrm{M}_{1}(46>37)$. Also, it cannot insert it between $\mathrm{M}_{1}$ and $\mathrm{M}_{2}$ for the same reason. Consequently, it inserts $P_{3}$ after $M_{2}$ and puts after it $P_{2}$ and finally $P_{1}$ (Fig. 6(2)).

Step2: It tries to improve plan's average tardiness by permutation process: in this step, the SMA tries to improve the average tardiness $\left(f_{1}\right)$ of the production jobs generated in step1. Table 2 describes production jobs characteristics (release date $r_{i}$, completion date $\widetilde{c_{i}}$, due date $d_{i}$ and tardiness $\widetilde{T}_{i}$ ) resulting after step1. The SMA constructs two lists: (1) a P list that contains tardy jobs and (2) a PA list that contains early jobs (PA can contain idle times ("A" jobs)). The SMA permutes each $P$ job with a PA job, computes $f_{1}$ and retains the one which best improves $f_{1}$. For our example, As illustrated in Fig. 6(3), as $P_{2}$ arrives at $t 39$, SMA permuted $P_{1}$ with an " $A$ " job (located between $\mathrm{CBM}_{i j}$ and $\mathrm{M}_{1}$ ). It permuted, after that, $\mathrm{P}_{2}$ with an "A" job (located between $\mathrm{P}_{1}$ and $\mathrm{M}_{1}$ ). Retained plan is illustrated in Fig. 6(4) and resulting calculations are summarized in Table 3.

(e.2) HRA $_{2}$ proposal evaluation: in this case, the SMA has only the position $\mathrm{t} 103$ where it can insert the $\mathrm{CBM}_{i j}$ (Fig. 7(0)). According to Table 4, there are still 32TU before reaching the deadline $\mathrm{DdlS}_{i}$ which is $100 t$. Thus, the MOS is retained and resulted CBM tardiness is $f_{2}=\operatorname{Max}(0,(103-8))=95$.

The SMA leaves $P_{3}$ and $P_{2}$ in their positions because the HRA proposed interval begins at $t 103$. It removes $P_{1}$ (Fig. $7(1)$ ) and inserts $\mathrm{CBM}_{i j}$ at $\mathrm{t} 103$ and after it the $\mathrm{P}_{1}$ (Fig. 7(2)). So, the retained plan will be the one illustrated in Fig. 7(3) and resulting calculations are summarized in Table 4.

Table 5 presents the two HRA proposals evaluation. We remark that the best proposal is the one of $\mathrm{HRA}_{1}$

\subsection{Multi-machine resolution}

After local resolution, the SMA's new schedule may affect the schedule of its neighbors: upstream or downstream machines. That's why we identify upstream and downstream inconsistency.

- Upstream inconsistency is identified when execution date $t_{i k}$ of production job $k$ on a machine $i$ is less than its completion date $c_{(i-1) k}$ on the upstream machine $\left(t_{i k}<c_{(i-1) k}\right)$.

- Downstream inconsistency is identified when completion date $c_{i k}$ of production job $k$ on machine $i$ is greater than its execution date $t_{(i+1) k}$ on the downstream machine $\left(c_{i k}>t_{(i+1) k}\right)$. 


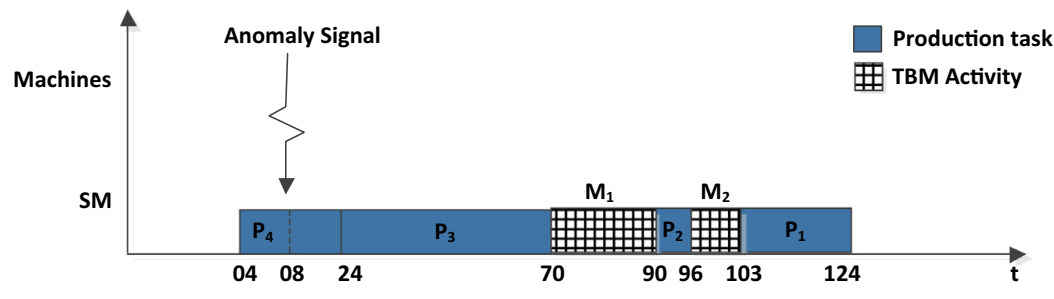

Fig. 5. SMA's current execution plan.

Table 1

Data relative to initial SMA execution plan.

\begin{tabular}{|c|c|c|c|c|c|c|c|c|}
\hline Task order & Task Id & Processing time & Starting date & Completion date & Release date & Due date & HR Id & Maint. type \\
\hline 1 & $\mathrm{P}_{4}$ & 20 & 4 & 24 & 0 & 60 & 1 & 1 \\
\hline 2 & $\mathrm{P}_{3}$ & 46 & 24 & 70 & 24 & 40 & 1 & I \\
\hline 3 & $\mathrm{M}_{1}$ & 20 & 70 & 90 & 1 & 1 & 2 & TBM \\
\hline 4 & $\mathrm{P}_{2}$ & 6 & 90 & 96 & 39 & 93 & 1 & 1 \\
\hline 5 & $\mathrm{M}_{2}$ & 7 & 96 & 103 & 1 & 1 & 1 & TBM \\
\hline 6 & $\mathrm{P}_{1}$ & 21 & 103 & 124 & 20 & 110 & 1 & 1 \\
\hline
\end{tabular}
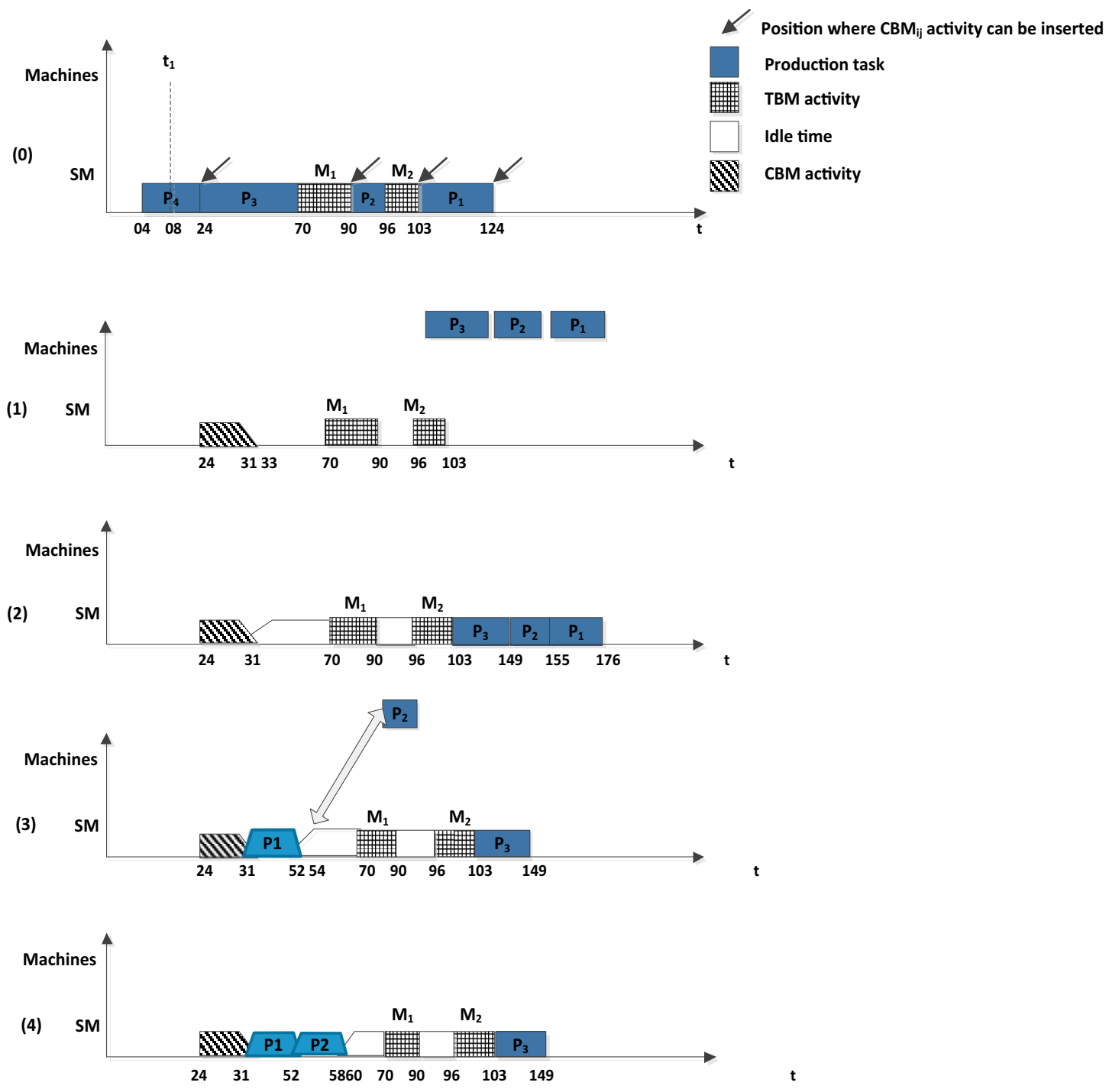

Fig. 6. Construction of the joint production and maintenance schedule according to $\mathrm{HRA}_{1}$ proposal. 
Table 2

Data relative to the intermediate schedule constructed according to $\mathrm{HRA}_{1}$ proposal.

\begin{tabular}{|c|c|c|c|c|c|c|c|c|c|c|c|}
\hline Tasks order & Tasks Id & Processing time & Stating date & Completion date & Release date & Due date & RH Id & Maint. type & Tardiness & $f_{1}$ & $f_{2}$ \\
\hline 1 & $\mathrm{CBM}_{i j}$ & $(4,7,9)$ & 24 & $(28,31,33)$ & 1 & 1 & 1 & CBM & 1 & 79 & 16 \\
\hline 4 & $A_{0}$ & 14 & $(28,31,33)$ & 70 & 1 & i & 1 & 1 & i & & \\
\hline 5 & $\mathrm{M}_{1}$ & 20 & 70 & 90 & l & i & 1 & TBM & 1 & & \\
\hline 6 & $\mathrm{~A}_{1}$ & 0 & 90 & 96 & 1 & 1 & 1 & 1 & 1 & & \\
\hline 7 & $\mathrm{M}_{2}$ & 7 & 96 & 103 & l & l & 2 & TBM & 1 & & \\
\hline 8 & $\mathrm{P}_{3}$ & 46 & 103 & 149 & 24 & 40 & 1 & 1 & 109 & & \\
\hline 3 & $\mathrm{P}_{2}$ & 6 & 149 & 155 & 39 & 93 & i & 1 & 62 & & \\
\hline 2 & $\mathrm{P}_{1}$ & 21 & 155 & 176 & 20 & 110 & i & 1 & 66 & & \\
\hline
\end{tabular}

Table 3

Data relative to the final schedule constructed according to $\mathrm{HRA}_{1}$ proposal.

\begin{tabular}{|c|c|c|c|c|c|c|c|c|c|c|c|}
\hline Tasks order & Tasks Id & Processing time & Stating date & Completion date & Release date & Due date & RH Id & Maint. type & Tardiness & $f_{1}$ & $f_{2}$ \\
\hline 1 & $\mathrm{CBM}_{i j}$ & $(4,7,9)$ & 24 & $(28,31,33)$ & 1 & 1 & 1 & CBM & 1 & 36.33 & 16 \\
\hline 2 & P1 & 21 & $(28,31,33)$ & $(49,52,54)$ & 20 & 110 & 1 & 1 & 0 & & \\
\hline 3 & P2 & 6 & $(49,52,54)$ & $(55,58,60)$ & 39 & 93 & i & i & 0 & & \\
\hline 5 & $\mathrm{M}_{1}$ & 20 & 70 & 90 & 1 & 1 & 1 & TВM & 1 & & \\
\hline 6 & $\mathrm{~A}_{1}$ & 6 & 90 & 96 & i & l & 1 & I & l & & \\
\hline 7 & $\mathrm{M}_{2}$ & 7 & 96 & 103 & 1 & 1 & 2 & TBM & 1 & & \\
\hline 8 & $\mathrm{P}_{3}$ & 46 & 103 & 149 & 24 & 40 & I & 1 & 109 & & \\
\hline
\end{tabular}

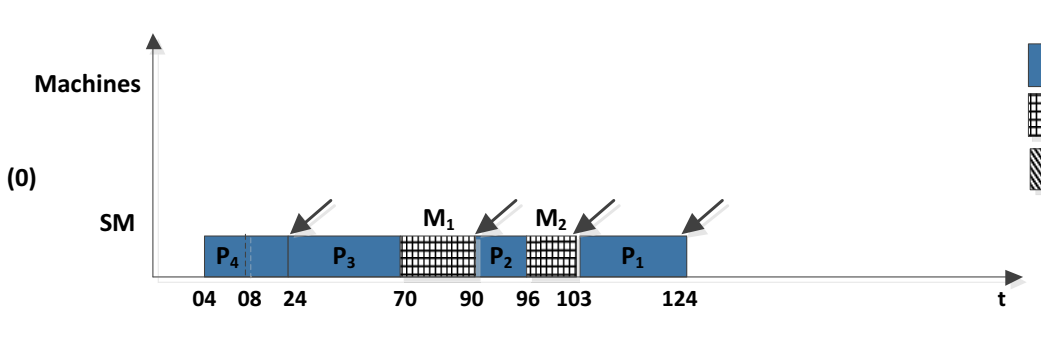

Position where $\mathrm{CBM}_{\mathrm{ij}}$ activity can be inserted

Production task

TBM activity

CBM activity
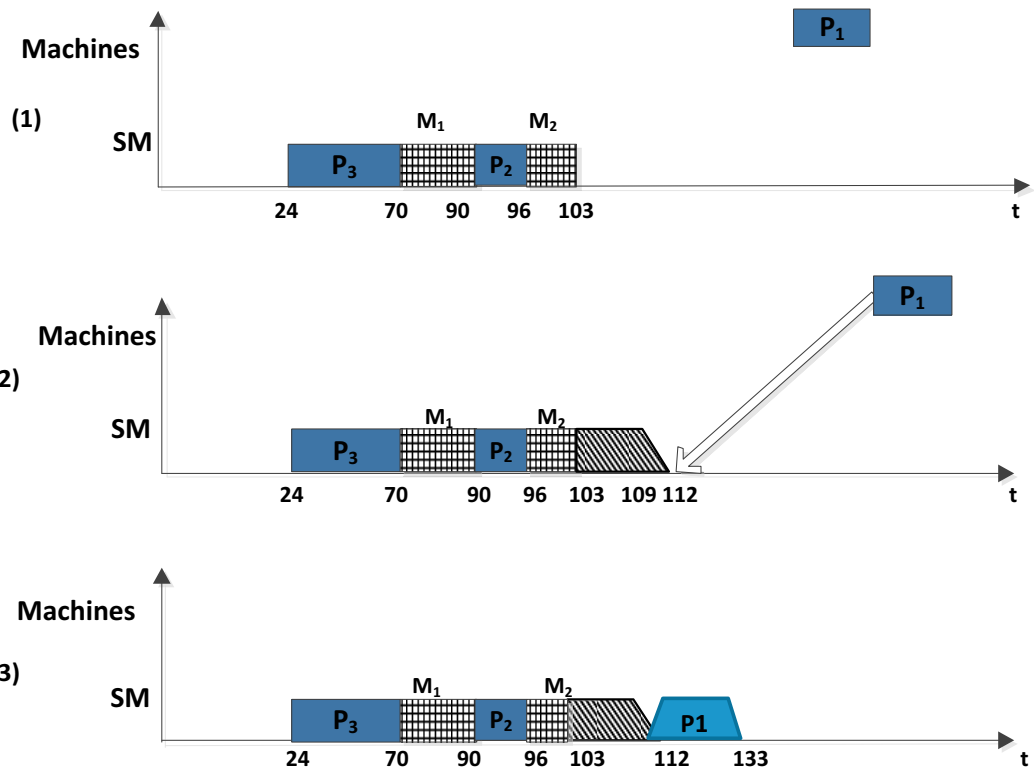

Fig. 7. Construction of the joint production and maintenance schedule according to $\mathrm{HRA}_{2}$ proposal.

Thus, a re-negotiation is unavoidable in order to readjust the actual schedule with respect to each machine local plan. According to the contacted MAs position, we identify the upstream negotiation and the downstream negotiation

\subsubsection{Upstream negotiation}

The upstream negotiation is necessary when a production job must be put forward (the job has to be executed before its completion date on the upstream machine: $\left.c_{(i-1) k}>t_{i k}\right)$. In this case, the SMA formulates an Update_Message (U_Message) in which it specifies concerned jobs. Also it specifies jobs that can be executed later according to its plan. It sends the U_Message to its UMA.

(a) U_Message Treatment: when a MA receives an U_Message, it tries to re-schedule production jobs of its plan according to the sender jobs order (Fig. 8). Two cases are possible: 
Table 4

Data relative to the final schedule constructed according to $\mathrm{HRA}_{2}$ proposal.

\begin{tabular}{|c|c|c|c|c|c|c|c|c|c|c|c|c|}
\hline $\begin{array}{l}\text { Tasks } \\
\text { order }\end{array}$ & $\begin{array}{l}\text { Tasks } \\
\text { Id }\end{array}$ & $\begin{array}{l}\text { Processing } \\
\text { time }\end{array}$ & Stating date & $\begin{array}{l}\text { Completion } \\
\text { date }\end{array}$ & $\begin{array}{l}\text { Release } \\
\text { date }\end{array}$ & $\begin{array}{l}\text { Due } \\
\text { date }\end{array}$ & $\begin{array}{l}\text { RH } \\
\text { Id }\end{array}$ & $\begin{array}{l}\text { Maint. } \\
\text { type }\end{array}$ & Tardiness & $\begin{array}{l}\text { TU Before } \\
\text { DdlS }\end{array}$ & $f_{1}$ & $f_{2}$ \\
\hline 1 & $\mathrm{P}_{3}$ & 46 & 24 & 70 & 24 & 40 & 1 & 1 & 30 & 38 & $(21,22,23)$ & 95 \\
\hline 2 & $\mathrm{M}_{1}$ & 20 & 70 & 90 & 1 & 1 & 2 & TBM & 1 & 38 & & \\
\hline 5 & $\mathrm{P}_{2}$ & 6 & 103 & 109 & 39 & 93 & 1 & 1 & 16 & 32 & & \\
\hline 4 & $\mathrm{M}_{2}$ & 7 & 96 & 103 & 1 & 1 & 1 & TBM & 1 & 32 & & \\
\hline 3 & $\mathrm{CBM}_{i j}$ & $(3,6,9)$ & 103 & $(106,109,112)$ & 1 & 1 & 2 & CBM & 1 & 1 & & \\
\hline 6 & $\mathrm{P}_{1}$ & 21 & $(106,109,112)$ & $(127,130,133)$ & 20 & 110 & I & 1 & $(17,20,23)$ & I & & \\
\hline
\end{tabular}

Table 5

Comparing HRA proposals.

\begin{tabular}{lll}
\hline HRA & HRA $_{1}$ & $\mathrm{HRA}_{2}$ \\
\hline$f_{1}=$ Average tardiness & 36.33 & $(21,22,23)$ \\
$f_{2}=$ CBM tardiness & 16 & 95 \\
$f=0.75 * f_{1}+0.25 * f_{2}$ & 31.2475 & $(39.5,40.25,41)$ \\
Retained HRA & $\mathrm{X}$ & \\
\hline
\end{tabular}

(a.1) It succeeds readjusting its local plan and absorbs inconsistency: In this case, it formulates an Information_Message (I_Message) in which it specifies new completion dates of jobs. It sends it to its downstream machine agent (DMA).

(a.2) It detects at its turn inconsistency with its upstream MA's (UMA) plan: in this case, if the considered machine is not the first one in the production line, it sends at its turn an U_Message to its UMA in order to try rescheduling its plan and so on until the total absorption of the inconsistency. Whereas, if the considered machine is the first one in the production line, it formulates an I_Message to its DMA to inform it of its final schedule.

(b) I_Message treatment: as explained before, a contacted MA can send an "I_Message" after modifying its own plan (Fig. 8). The receiver of this message has to readjust its plan according to the sender job completion dates. If the receiver is not the last MA in the production line, it sends at its turn an I_Message to its DMA in order to inform it of the new dates.

\subsubsection{Downstream negotiation}

At the end of upstream negotiation, the SMA updates its plan. This plan may not be similar to local resolution approach one because it depends on the last received I_Message. If the new schedule affects the one of its DMA, the SMA formulates an I_Message and sends it to the DMA. Consequently, this stage is a propagation of resulted schedules to all downstream machine agents (Fig. 9).

\section{Experimental results}

In this chapter, we present results of a series of computational experiments conducted to test the effectiveness of the newly proposed approach. We use a personal computer with an Intel processor Core i3, $2.53 \mathrm{GHz}$ (4 CPUs), 4 Go of RAM and Windows7 (32 bits) operating system. In what follows, we describe first, simulation software, material and design. After that, we present and discuss results of experiments.

\subsection{Simulation material and software}

Different set of inputs are tested using ETOMA (Bouzidi-Hassini, Saboun, Bourahla, Benbouzid-Sitayeb, \& Khelifati, 2014), a multiagent framework dedicated to developing and testing production and maintenance schedules. It is composed of three modules. The

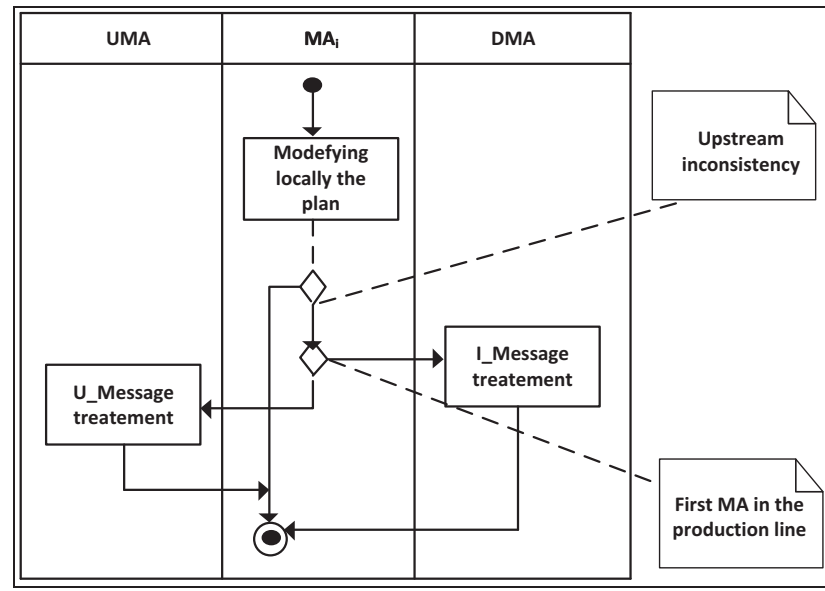

Fig. 8. U_Message treatment activity.

first one called Develop defines the user multi-agents' solution by defining all system agents and their behavior. The second one called Test manages tests and the third one called Blackboard insures communication between the two previous modules. ETOMA does not impose any architecture for the system that represents the workshop nether for agents to be defined by users. It covers the three shops' configuration: Flow-shop, Job-shop and Open-shop.

\subsection{Simulation design}

We consider for our experiments a flow-shop with release and due dates. To our knowledge, there is no instance for the joint production and maintenance scheduling problem as it is defined in our approach. Therefore, we generate data relative to production, maintenance and human resources. We generate different predictive plans composed of production and maintenance tasks scheduled jointly. After that, we simulate the arrival of anomaly event and we observe the behavior of our system. The date of anomaly arrival can be at the beginning, middle or end of the scheduling horizon in order to study all possible scenarios.

\subsubsection{Production data}

Due to lack of benchmarks that take into consideration release and due dates for each production job, we generate our own instances. We adapt the Taillard benchmarks (Taillard, 1993) by generating release date $r_{i j}$ and due date $d_{i j}$ for each job $j$ on a machine $i$ according to respectively (Eqs. (5) and (6)).

$r_{i j}=r_{(i-1) j}+p_{(i-1) j}$

$d_{i j}=\left(d_{j}-r_{j}\right) * p_{i j} / p_{j}$

\subsubsection{Predictive joint production and maintenance schedules}

For each machine, several TBM activities are planned. Their processing times are randomly generated from an interval fixed by 


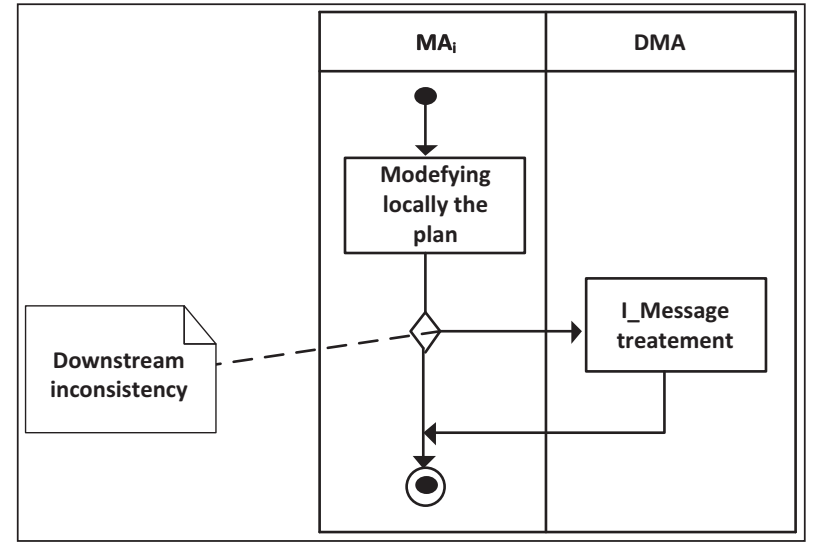

Fig. 9. I_Message treatment activity.

user. Maintenance activities cannot be planned randomly because it depends on machines' operating duration. A period $T_{j}$ between two maintenance activities of type $j$ is calculated as follows (Eq. (7)):

$T_{j}=\mathrm{MP}_{j} * \mathrm{NPT}$

where $\mathrm{MP}_{j}$ represents the average processing time of production jobs that will be executed on the machine, NPT the number of production jobs between two maintenance activities. It's a parameter that can be fixed by user. In our simulations we took NPT $=4$.

\subsubsection{Human resource instances}

We vary HRA number between 2 and 8 in order to evaluate its influence on the approach performances. We stopped on 8 HRAs because we have only one CBM activity to insert at a time.

If there are multiple CBM activities with different resolution times to be inserted in between production process, the SMA treats CBM activities one by one.

We generate an availability plan for each $\mathrm{HRA}_{m}$ in the workshop. It depends on the maintenance activities number planned on machines and also on the number of existent human resources in the maintenance service. Consequently, the average period $\mathrm{TRH}_{m}$ that separates two interventions of any $\mathrm{HRA}_{m}$ is calculated according to (Eq. (8)).

$\mathrm{TRH}_{m}=p / \mathrm{HRN}_{m}$

$\mathrm{HRN}_{m}=\mathrm{NMA} / \mathrm{NHR}$

where $p$ represents the scheduling horizon, $\mathrm{HRN}_{m}$ the average number of maintenance activities affected to $\mathrm{HRA}_{m}$, it is calculated according to (Eq. (9)). NMA is the total number of planned maintenance activities and NHR is the number of existent human resources in the maintenance service.

In order to construct an $\mathrm{HRA}_{m}$ plan, we calculate its availability intervals $\mathrm{IA}_{m}=\left\{\mathrm{IA}_{m 1}, \mathrm{IA}_{m 2}, \ldots\right\}$. Each interval $\mathrm{IA}_{m k}$ is defined as $\left[\right.$ IAmin $_{m k}$, IAmax $_{m k}$ ] (Eqs. (10) and (11)).

$\mathrm{IAmin}_{m k}=\mathrm{IAmax}_{m k-1}+p_{m p}^{\prime \prime}+\alpha_{1}$

$\operatorname{IAmax}_{m k}=\operatorname{IAmin}_{m k}+\mu * p_{m p}^{\prime \prime}+\alpha_{2}$

$\alpha_{1}$ and $\alpha_{2}$ are random numbers with $-p_{m p}^{\prime \prime} / 2<=\alpha_{1}<=2 * p_{m p}^{\prime \prime} / 3$ and $0<=\alpha_{2}<=2 * p_{m p}^{\prime \prime}, \mu$ is a coefficient that characterizes interval width $\{3$ for long, 2 for middle, 1 for small $\}$.

\subsubsection{Fuzzy data}

Base width $b w$ of the membership function (Fig. 10) represents the distance between the most probable value of the fuzzy measure and its maximum or minimum value.

As known, we proposed two fuzzy measures: $R U L_{i}$ and $p_{j m}^{\prime \prime}$. The choice of $b w$ value has an impact on resolution approach results.

For $\mathrm{RUL}_{i}$, the $b w$ value influences interval widths of both MOS and POS. In fact, there is no sense for strategies existence if we consider a very large interval nether a very short interval for maintenance strategies. Because if the interval is very large, results may be unrealistic. Also, when it is very short, the probability of finding available HRAs for CBM execution will be very small. The aim of considering a deadline for CBM planning is to evaluate the case of planning CBM while delaying production jobs and the case of keeping actual schedule unchanged by delaying CBM planning. So it is important to propose a realistic length for maintenance strategies interval. For these reasons, we choose the value 0.4 for $b w$ of the $\mathrm{RUL}_{i}\left(t_{f} \pm t_{f} * 0.40\right)$.

Whereas, $b w$ of $p_{j m}^{\prime \prime}$ influences the number of possible positions where CBM can be inserted. We choose the value 0.2 $\left(p_{j m}^{\prime \prime} \pm p_{j m}^{\prime \prime} * 0.2\right)$ which is medium and reflects a rational imprecision regarding processing time for maintenance activities.

\subsubsection{Simulating the anomaly arrival}

In order to study the influence of anomaly's arrival date, we generate a signal at beginning, middle and end of the SMA's plan. Therefore, we divide the SMA's plan on three equivalent intervals. For every experiment to be executed, we generate a signal randomly in one of these intervals. For the SMA's order in the flow-shop, we select in each benchmark, the middle machine to obtain significant results.

\subsection{Simulation results}

We report on three sets of experiments. In the first experiments set, we evaluate the system reactivity by measuring the influence of machines number $m_{0}$, jobs number $m_{1}$, human resources' number $m_{4}$, the adopted strategy and, the moment of anomaly arrival on the resolution time. In the second one, we evaluate the capacity of our approach to minimize the average production lateness. Finally, in the last experimental set, we measure the effect of each sub-objective function $f_{1}$ and $f_{2}$ on the global objective function $f$.

\subsubsection{System's reactivity}

System's reactivity is an important propriety in the online (reactive) phase of scheduling. It is the resolution time taken to insert a CBM activity in the current schedule. In order to evaluate this propriety, we vary machines number $\left(m_{0}\right)$, jobs number $\left(m_{1}\right)$ and human resources number $\left(m_{4}\right)$. We compute after that, the resulting resolution time in the one-machine and multi-machine resolution phases. We simulate the anomaly event arrival at the beginning; middle and end of the schedule. We apply both maintenance oriented (MOS) and production oriented strategy (POS) for maintenance planning in order to analyze results. Results are reported in Table 6.

According to Table 6, one can notice that multi-machine resolution time is always lower than the one-machine resolution time. In fact, the inconsistency has been detected rarely between machines, which mean that proposed one-machine resolution approach has absorbed the event of inserting the new CBM without disturbing the other machine schedules.

Human resources number does not influence the multimachine resolution time; it influences only the one-machine resolution one because HRA with MCA and SMA negotiate CBM planning. In most cases, when HRA number increases, one-machine 


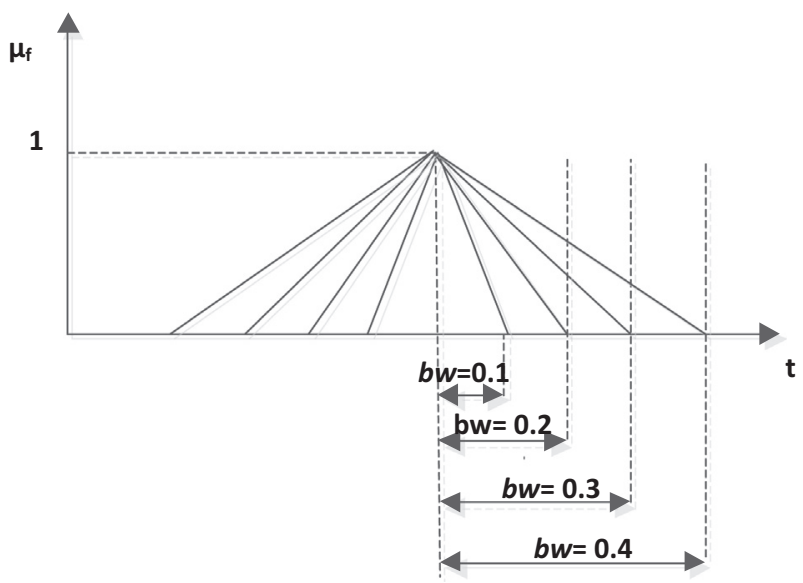

Fig. 10. Base width " $b w$ " of the membership function.

resolution time increases but stills reasonable (less than $10 \mathrm{~s}$ ). We remark in certain cases that increasing the HRA number does not necessarily increase the resolution time (ex. the two gray cases in Table 6). It depends on HRA availability. The existence of 8 HRA at the maintenance service does not mean that the 8 HRA are available for intervention.

When jobs number increases, one-machine resolution time increases too because SMA, after inserting CBM activity, has to reschedule an important number of production jobs which significantly increases the resolution time. Increasing jobs number increases multi-machine resolution time but not with the same degree as one-machine resolution time because inconsistency has been detected rarely and so upstream or downstream negotia- tions number is small. It increases because the SMA neighbor machines if they have to readjust their schedules, they will reschedule an important number of jobs which will take time.

Also, results shown that one-machine resolution time is higher when MOS strategy is adopted because the number of jobs to readjust is greater than the one when POS is adopted. This is due to the interval width of MOS strategy which is larger than the POS one.

4.3.2. Measuring the contribution of both production tardiness and CBM tardiness in the global objective function

In this series of experiments, we compare both production and CBM tardiness values in order to measure their effect on global objective function value. We compare also the initial production tardiness $f_{10}$ with $\widetilde{f}_{1}$ after inserting CBM activity (as $f_{10}$ is exact, we compare it with the maximal value of $\widetilde{f_{1}}$ ). We analyze the case of anomaly arrival at the middle of the predictive plan. Results are summarized in Table 7.

We remark that when human resources number increases, production tardiness decreases. We can explain this result by the fact that SMA evaluates all HRA proposals and chooses the one that minimizes jobs tardiness. When proposals number is important, the probability to not increasing jobs tardiness is high.

When machines and jobs number increase, production tardiness increases. In fact, tardiness of a given job depends on tardiness of its previous jobs. If these latter are late, automatically the actual job will be late and its tardiness is the sum of previous jobs tardiness on the different upstream machines.

We can remark also that as CBM tardiness is calculated according to the date where CBM activity will be planned (Section 2.3), its value is always higher than the production tardiness value. Moreover, when MOS is followed, production tardiness is important and

Table 6

Influence of jobs, machines and human resources number on the resolution time.

\begin{tabular}{|c|c|c|c|c|c|c|c|c|c|c|c|c|c|c|}
\hline \multirow[t]{3}{*}{$m_{0}$} & \multirow[t]{3}{*}{$m_{1}$} & \multirow[t]{3}{*}{$m_{4}$} & \multicolumn{6}{|c|}{ One-machine resolution (ms) } & \multicolumn{6}{|c|}{ Multi-machine resolution (ms) } \\
\hline & & & \multicolumn{2}{|c|}{ Beginning } & \multicolumn{2}{|l|}{ Middle } & \multicolumn{2}{|l|}{ End } & \multicolumn{2}{|c|}{ Beginning } & \multicolumn{2}{|c|}{ Middle } & \multicolumn{2}{|l|}{ End } \\
\hline & & & MOS & POS & MOS & POS & MOS & POS & MOS & POS & MOS & POS & MOS & POS \\
\hline \multirow[t]{9}{*}{5} & \multirow[t]{3}{*}{20} & 2 & 40.21 & 31.33 & 34.52 & 23.65 & 20.21 & 21.33 & 7.00 & 3.33 & 4.23 & 1.50 & 2.05 & 1.75 \\
\hline & & 4 & 55.56 & 40.35 & 45.33 & 55.63 & 25.55 & 20.33 & & & & & & \\
\hline & & 8 & 70.33 & 42.36 & 80.25 & 65.33 & 20.33 & 22.25 & & & & & & \\
\hline & \multirow[t]{3}{*}{50} & 2 & 120.33 & 80.33 & 130.25 & 136.23 & 120.23 & 100.23 & 20.33 & 16.33 & 13.89 & 13.67 & 12.56 & 12.86 \\
\hline & & 4 & 200.33 & 100.55 & 253.33 & 152.33 & 150.33 & 145.33 & & & & & & \\
\hline & & 8 & 213.66 & 125.36 & 363.23 & 226.3 & 223.36 & 235.33 & & & & & & \\
\hline & \multirow[t]{3}{*}{100} & 2 & 200.23 & 145.33 & 123.66 & 130.33 & 123.33 & 140.25 & 24.44 & 21.56 & 17.89 & 17.11 & 13.78 & 12.44 \\
\hline & & 4 & 250.36 & 150.33 & 223.33 & 250.23 & 223.33 & 189.33 & & & & & & \\
\hline & & 8 & 286.33 & 160.25 & 250.23 & 200.33 & 260.33 & 190.66 & & & & & & \\
\hline \multirow[t]{9}{*}{10} & \multirow[t]{3}{*}{20} & 2 & 465.33 & 333.25 & 330.25 & 236.25 & 300.33 & 350.25 & 28.00 & 26.22 & 14.22 & 13.33 & 12.00 & 11.78 \\
\hline & & 4 & 350.25 & 245.33 & 320.25 & 250.25 & 250.23 & 220.36 & & & & & & \\
\hline & & 8 & 250.25 & 260.33 & 350.25 & 360.25 & 325.25 & 356.3 & & & & & & \\
\hline & \multirow[t]{3}{*}{50} & 2 & 350.5 & 265.33 & 460.36 & 350.25 & 356.62 & 250.25 & 22.33 & 20.44 & 17.44 & 17.56 & 15.26 & 12.85 \\
\hline & & 4 & 365.23 & 277.33 & 420.25 & 450.25 & 450.23 & 350.23 & & & & & & \\
\hline & & 8 & 425.55 & 330.25 & 450.25 & 400.25 & 350.25 & 325.25 & & & & & & \\
\hline & \multirow[t]{3}{*}{100} & 2 & 678.55 & 550.25 & 700.25 & 650.25 & 500.25 & 650.25 & 36.33 & 33.25 & 22.22 & 21.11 & 10.33 & 9.67 \\
\hline & & 4 & 650.33 & 454.33 & 650.25 & 500.85 & 423.36 & 350.25 & & & & & & \\
\hline & & 8 & 780.23 & 550.25 & 885.25 & 900.25 & 650.52 & 589.25 & & & & & & \\
\hline \multirow[t]{9}{*}{20} & \multirow[t]{3}{*}{20} & 2 & 120.33 & 50.33 & 220.36 & 120.25 & 200.25 & 140.25 & 28.03 & 28.25 & 24.78 & 23.40 & 11.89 & 13.00 \\
\hline & & 4 & 253.33 & 298.23 & 265.25 & 270.25 & 198.23 & 150.23 & & & & & & \\
\hline & & 8 & 986.33 & 1120.33 & 1125.25 & 1203.25 & 985.25 & 900.55 & & & & & & \\
\hline & \multirow[t]{3}{*}{50} & 2 & 1985.33 & 1325.25 & 2540.33 & 1983.33 & 1203.25 & 956.56 & 31.35 & 23.25 & 27.56 & 16.33 & 17.78 & 16.50 \\
\hline & & 4 & 2536.36 & 2352.33 & 2436.33 & 2456.33 & 2123.25 & 1985.25 & & & & & & \\
\hline & & 8 & 4536.33 & 3256.33 & 4856.33 & 3562.33 & 2003.25 & 2013.25 & & & & & & \\
\hline & \multirow[t]{3}{*}{100} & 2 & 7965.33 & 4134.00 & 6402.33 & 5360.23 & 3652.25 & 2546.35 & 49.58 & 42.65 & 35.25 & 35.25 & 18.00 & 19.89 \\
\hline & & 4 & 8563.33 & 5840.00 & 6135.33 & 4652.33 & 4563.25 & 3252.25 & & & & & & \\
\hline & & 8 & 9563.22 & 7862.00 & 9635.33 & 8523.33 & 6523.23 & 6235.23 & & & & & & \\
\hline
\end{tabular}


Table 7

Objective functions in the case of anomaly arrival at the middle.

\begin{tabular}{|c|c|c|c|c|c|c|c|c|c|}
\hline \multirow[t]{2}{*}{$m_{0}$} & \multirow[t]{2}{*}{$m_{1}$} & \multirow[t]{2}{*}{$m_{4}$} & \multirow[t]{2}{*}{$f_{10}$} & \multicolumn{2}{|c|}{ Production tardiness $\tilde{f}_{1}$} & \multicolumn{2}{|c|}{ CBM tardiness $f_{2}$} & \multicolumn{2}{|l|}{ Objective function $\tilde{f}$} \\
\hline & & & & MOS & POS & MOS & POS & MOS & POS \\
\hline \multirow[t]{9}{*}{5} & \multirow[t]{3}{*}{20} & 2 & 0.00 & 0 & 0.00 & 84.00 & 251.00 & 21 & 188.25 \\
\hline & & 4 & 0.00 & 0 & 0 & 94.00 & 324.00 & 23.5 & 243 \\
\hline & & 8 & 0.00 & 0 & 0 & 44.00 & 317.00 & 11 & 237.75 \\
\hline & \multirow[t]{3}{*}{50} & 2 & 16.00 & $(12,15,18)$ & $(7.2,9,10.8)$ & 97.00 & 403.00 & $(33.25,35.5,37.75)$ & $(304.05,304.5,304.95)$ \\
\hline & & 4 & 16.00 & $(10.4,13,15.6)$ & $(9.6,12,14.4)$ & 93.00 & 318.00 & $(31.05,33,34.95)$ & $(240.9,241.5,242.1)$ \\
\hline & & 8 & 16.00 & $(8,10,12)$ & $(5.6,7,8.4)$ & 33.00 & 296.00 & $(14.25,15.75,17.25)$ & $(223.4,223.75,224.1)$ \\
\hline & \multirow[t]{3}{*}{100} & 2 & 11.00 & $(10.4,13,15.6)$ & $(7.2,9,10.8)$ & 33.00 & 176.00 & $(16.05,18,19.95)$ & $(133.8,134.25,134.7)$ \\
\hline & & 4 & 11.00 & $(8.8,11,13.2)$ & 10 & 14 & 366.00 & $(10.1,11.75,13.4)$ & 277 \\
\hline & & 8 & 11.00 & 10.5 & 9 & 101.00 & 452.00 & 33.125 & 341.25 \\
\hline \multirow[t]{9}{*}{10} & \multirow[t]{3}{*}{20} & 2 & 32.00 & $(20,25,30)$ & $(19.2,24,28.8)$ & 74.00 & 265.00 & $(33.5,37.25,41)$ & $(203.55,204.75,205.95)$ \\
\hline & & 4 & 32.00 & $(20,25,30)$ & $(15.2,19,22.8)$ & 50.00 & 328.00 & $(27.5,31.25,35)$ & $(249.78,250.75,251.7)$ \\
\hline & & 8 & 32.00 & $(35.2,44,52.8)$ & $(24.8,31,37.2)$ & 29.00 & 562.00 & $(33.65,40.25,46.85)$ & $(427.7,429.25,430.8)$ \\
\hline & \multirow[t]{3}{*}{50} & 2 & 38.00 & $(16.8,21,25.2)$ & 5.00 & 147.00 & 553.00 & $(49.35,52.5,55.65)$ & 416 \\
\hline & & 4 & 38.00 & 38.00 & $(16,20,24)$ & 10.00 & 336.00 & 31 & $(256,257,258)$ \\
\hline & & 8 & 38.00 & $(31.2,39,46.8)$ & $(16,20,24)$ & 68.00 & 345.00 & $(40.4,46.25,52.1)$ & $(262.75,263.75,264.75)$ \\
\hline & \multirow[t]{3}{*}{100} & 2 & 86.00 & $(59.2,74,88.8)$ & $(32,40,48)$ & 56.00 & 380.00 & $(58.4,69.5,80.6)$ & $(293,295,297)$ \\
\hline & & 4 & 86.00 & $(52,65,78)$ & $(35.2,44,52.8)$ & 3.00 & 352.00 & $(39.75,49.5,59.25)$ & $(272.8,275,277,5)$ \\
\hline & & 8 & 86.00 & $(48,60,72)$ & $(52.8,66,79.2)$ & 15.00 & 227.00 & $(39.75,48.75,57.75)$ & $(183.45,186.75,190.05)$ \\
\hline \multirow[t]{9}{*}{20} & \multirow[t]{3}{*}{20} & 2 & 570.00 & $(432,540,648)$ & $(451.2,564,676.8)$ & 86.00 & 522.00 & $(345.5,426.5,507.5)$ & $(504.3,532.5,560.7)$ \\
\hline & & 4 & 570.00 & 568.33 & $(411.2,514,616.8)$ & 244.00 & 293.00 & 487.25 & $(322.55,348.25,373.95)$ \\
\hline & & 8 & 570.00 & 576.00 & $(405.6,507,608.4)$ & 15 & 330.00 & 435.75 & $(348.9,374.25,399.6)$ \\
\hline & \multirow[t]{3}{*}{50} & 2 & 311.00 & 310.00 & 306.00 & 66.00 & 431.00 & 249 & 399.75 \\
\hline & & 4 & 311.00 & 308.00 & 311.00 & 64.00 & 451.00 & 247 & 416 \\
\hline & & 8 & 311.00 & $(197.6,247,296.4)$ & 311.00 & 69.00 & 312.00 & $(165.45,202.5,239.55)$ & 311.75 \\
\hline & \multirow[t]{3}{*}{100} & 2 & 193.00 & $(88.8,111,133.2)$ & $(122.4,153,183.6)$ & 51.00 & 278.00 & $(79.35,96,112.65)$ & $(293.1,246.75,254.4)$ \\
\hline & & 4 & 193.00 & 432.00 & 150.00 & 23 & 276.00 & 104.75 & 244.5 \\
\hline & & 8 & 193.00 & $(96.8,121,145.2)$ & 152.00 & 22.23 & 342.00 & $(78.16,96.04,114.46)$ & 294.5 \\
\hline
\end{tabular}

Table 8

One-machine and multi-machine tardiness according to the maintenance strategy adopted and human resources number.

\begin{tabular}{|c|c|c|c|c|c|c|c|c|c|c|c|c|}
\hline \multirow[t]{3}{*}{$m_{4}$} & \multicolumn{6}{|c|}{ One-machine tardiness } & \multicolumn{6}{|c|}{ Multi-machine tardiness } \\
\hline & \multicolumn{2}{|c|}{ Unchanged } & \multicolumn{2}{|l|}{ Improved } & \multicolumn{2}{|c|}{ Deteriorated } & \multicolumn{2}{|c|}{ Unchanged } & \multicolumn{2}{|l|}{ Improved } & \multicolumn{2}{|c|}{ Deteriorated } \\
\hline & MOS (\%) & POS (\%) & MOS (\%) & POS (\%) & MOS (\%) & POS (\%) & $\operatorname{MOS}(\%)$ & POS (\%) & MOS (\%) & POS (\%) & $\operatorname{MOS}(\%)$ & POS (\%) \\
\hline 2 & 32.85 & 31.13 & 65 & 62.23 & 2.15 & 6.64 & 77.90 & 77.14 & 20.40 & 21.63 & 1.70 & 1.23 \\
\hline 4 & 35.67 & 32.34 & 61 & 65.31 & 3.33 & 2.35 & 77.14 & 83.42 & 22.66 & 13.33 & 3.25 & 3.25 \\
\hline 8 & 32.74 & 31.29 & 62 & 60.37 & 5.26 & 8.34 & 71.80 & 72.41 & 25.26 & 25.12 & 2.94 & 2.47 \\
\hline
\end{tabular}

CBM tardiness is small and vice versa when POS is applied. Consequently, the objective function value is small when MOS is adopted

In conclusion, the results of MOS are better than those of production oriented one because it offers minimal CBM tardiness and a much closed production tardiness to the one offered by POS. But if the aim is to minimize the reaction time, POS is more interesting.

\subsubsection{Capacity of the approach to absorb the average production tardiness}

In this section, we compare average production tardiness on the SMA before and after the CBM activity insertion. Moreover, we compare the global average production tardiness that can be detected on the last machine in the flow-shop. For every test executed, we noted how many times the average production tardiness has been improved, was unchanged or has increased. Results are presented in Table 8. One can notice that whatever human resources' number or the adopted maintenance strategy, in more than $60 \%$ of cases, the one-machine production tardiness has been improved and in more than $70 \%$ of cases, the Multi-machine production tardiness has been unchanged which means that the goal of disturbing at least the actual plan has been achieved.

\section{Conclusion and future work}

In this work, we proposed a reactive model which responses to the event of inserting new CBM activity. We propose a partial re-scheduling in order to maintain stability in the workshop with a two-level resolution process: one-machine and multi-machine resolution. We propose also two maintenance strategies for planning CBM activity: Maintenance oriented and production oriented strategy.

The one-machine resolution describes the SMA's behavior in response to the anomaly event apparition. Whereas the multimachine resolution describes behavior of adjacent machines in case of inconsistency detection between machines' schedules. Uncertainty is considered by proposing fuzzy estimation of the equipment RUL and CBM processing time.

In order to measure the proposed method performances, we made several series of tests. Results shown that adopted onemachine resolution could absorb locally the event and minimizes the global tardiness of the whole production jobs in the workshop. Also, MOS offered best results in term of production and CBM tardiness. In term of reaction time, POS is more interesting in the case of anomaly arrival at the end. 
There are several directions in which this research can be extended. In this paper, we do not consider human resources competence formulation. It could be interesting to consider a formulation of competence profiles in order to allocate maintenance activities to the best human resource based on its competence and not only based on its estimation of processing time. Another direction consists on considering other events like machines' breakdowns and human resources' defection.

\section{References}

Aloulou, M. A., \& Croce, F. D. (2008). Complexity of single machine scheduling problems under scenario-based uncertainty. Operations Research Letters, 36 , 338-342.

Altuger, G., \& Chassapis, C. (2009). Multi criteria preventive maintenance scheduling through arena based simulation modeling. in Proceedings of the 2009 IEEE winter simulation conference, Austin, TX

Bach, K., Althoff1, K. D., Newo, R., \& Stahl, A. (2011). A case-based reasoning approach for providing machine diagnosis from service reports, in case-based reasoning research and development. Lecture Notes in Computer Science, 6880, 363-377.

Benbouzid, F., Varnier, C., \& Zerhouni, N. (2003). Resolution of joint maintenance/ production scheduling by sequential and integrated strategies. In 7th international work conference on artificial and natural neural networks IWANN2003, 3-6 June, Spain. Proceedings LNCS 2687 (pp. 782-789).

Benbouzid-Sitayeb, F., Guelbi, S. A., Bessadi, Y., Varnier, C., \& Zerhouni, N. (2011). Joint scheduling of jobs and preventive maintenance operations in the flowshop sequencing problem: A resolution with sequential and integrated strategies. International Journal of Management Research (IJMR), 6(1), 30-48.

Benmansour, R., Allaoui, H., Artiba, A., Iassinovski, S., \& Pellerin, R. (2011). Simulation-based approach to joint production and preventive maintenance scheduling on a failure-prone machine. Journal of Quality in Maintenance Engineering, 17(3), 254-267.

Billaut, J. C., Moukrim, A., \& Sanlaville, E. (2005). Flexibilité et robustesse en ordonnancement. Traité IC2 (pp. 15-34). Paris: Hermes Science.

Bouzidi-Hassini, S., Saboun, Y., Bourahla, S., Benbouzid-Sitayeb, F., \& Khelifati, S. (2014). ETOMA: A multi-agent tool for shop scheduling problems. In Advanced approaches to intelligent information and database systems. Studies in Computational Intelligence (Vol. 551, pp. 79-88).

Brandolese, M.. Fransi, M., \& Pozzeti, A. (1996). Production and maintenance integrated planning. International Journal of Production Research, 34(7), 2059-2075.

Campos, J. (2009). Development in the application of ICT in condition monitoring and maintenance. Computers in Industry, 60(1), 1-20.

Chaabi, T. (2010). Un algorithme génétique pour l'ordonnancement robuste: Application au problème du flow shop hybride. Thèse de doctorat. l'Université de Valenciennes et du Hainaut-Cambrésis. France.

Chanas, S., \& Kasperski, A. (2001). Minimizing maximum lateness in a single machine scheduling problem with fuzzy processing times and fuzzy due dates. Engineering Applications of Artificial Intelligence, 14, 377-386.

Chebel-Morello, B., Haouchine, K., \& Zerhouni, N. (2009). A methodology to conceive a case based system of industrial diagnosis. In World congress of engineering asset management, Greece.

Cox, J. F., \& Blackstone, John H. Jr. (Eds.). (1991). APICS dictionary (7th ed.. Falls Church, VA: APICS.

De Snoo, C., Van Wezel, W., Wortmann, J. C., \& Gaalman, G. J. C. (2011). Coordination activities of human planners during rescheduling: Case analysis and event handling procedure. International Journal of Production Research, 49(7), $2101-2122$.

Dorn, J., Kerr, R., \& Thalhammer, G. (1993). Reactive scheduling in a fuzzy-temporal framework. In Proceedings of international workshop on knowledge-based reactive scheduling (pp. 39-55).

Dubois, D., \& Prade, H. (1985). Théorie des possibilités: Applications à la représentation des connaissances en informatique, Masson, Paris.

Dumitru, V., \& Luban, F. (1982). Membership functions, some mathematical programming models and production scheduling. Fuzzy Sets and Systems, 8, 19-33.

Gupta, A., \& Lawsirirat, C. (2006). Strategically optimum maintenance of monitoring-enabled multi-component systems using continuous-time jump deterioration models. Journal of Quality in Maintenance Engineering, 12(3), 306-329.

Guyon, O., Lemaire, P., Pinson, É., \& Rivreau, D. (2010). Cut generation for an integrated employee timetabling and production scheduling problem. European Journal of Operational Research, 201(2), 557-567.

Hanemann, A. (2006). A hybrid rule-based/case-based reasoning approach for service fault diagnosis. In Proceedings of 20th international conference on advanced information networking and applications, Austria.
Huang, L. J., Jiang, H., Chen, Y., \& Chen, S. J. (2014). Using condition-based maintenance and reliability-centered maintenance to improve maintenance in nuclear power plants. Progress of nuclear safety for symbiosis and sustainability: Advanced digital instrumentation, control and information systems for nuclear power plants (Vol. 177). Japan: Springer.

Jones, A., \& Rabelo, L. C. (1998). Survey of job shop scheduling techniques. Gaithersburg, MD, USA: NISTIR-National Institute of Standards and Technology. <http://www.mel.nist.gov/msidlibrary/doc/luis.pdf>.

Khelifati, S., \& Benbouzid-Sitayeb, F. (2011). A multi-agent approach for scheduling jobs and maintenance operations in the flowshop sequencing problem. International Journal of Intelligent Engineering Informatics, 2(1), 47-70.

Kouiss, K., Pierreval, H., \& Mebarki, N. (1997). Using multi-agent architecture in FMS for dynamic scheduling. Journal of Intelligent Manufacturing, 8, 41-47.

Kulscar, G., \& Forrai, M. Kulscarine (2009). Solving multi-objective production scheduling problems using a new approach. Production Systems and Information Engineering, 5, 81-94.

Lee, C. Y., \& Chen, Z. L. (2000). Scheduling jobs and maintenance activities on parallel machines. Naval Research Logistics, 47, 145-165.

Legat, V., Zaludova, A. H., Cervenka, V., \& Jurca, V. (1996). Contribution to optimization of preventive maintenance. Journal of Reliability Engineering and System Safety, 51, 259-266.

Li, X., Zhang, C., Gao, L., Li, W., \& Shao, X. (2010). An agent-based approach for integrated process planning and scheduling. Journal of Expert Systems with Applications, 37, 1256-1264.

Marmier, F., Varnier, C., \& Zerhouni, N. (2009). Proactive, dynamic and multi-criteria scheduling of maintenance activities. International Journal of Production Research, 47(8), 2185-2220.

Martorell, S., Villamizar, M., Carlos, S., \& Sanchez, A. (2010). Maintenance modeling and optimization integrating human and material resources. International Journal of Reliability Engineering and System Safety, 95, 1293-1299.

Matsveichuk, N. M., Sotskov, Yu N., Egorova, N. M., \& Lai, T. (2009). Schedule execution for two-machine flow-shop with interval processing times. Mathematical and Computer Modelling, 49(5-6), 991-1011.

Ouelhadj, D., \& Petrovic, S. (2009). A survey of dynamic scheduling in manufacturing systems. Journal of Scheduling, 12(4), 417-431.

Owliya, M., Saadat, M., Goharian, M., \& Anane, R. (2010). Agents-based interaction protocols and topologies in manufacturing task allocation. In Proceeding of the 5th international conference on system of systems engineering.

Pereira, C. M. N. A., Lapa, C., Mol, A. C. A., \& da Luz, A. F. (2010). A particle swarm optimization (PSO) approach for non-periodic preventive maintenance scheduling programming. Progress in Nuclear Energy, 52(8), 710-714.

Petrovic, S., Petrovic, D., \& Burke, E. (2011). Fuzzy logic-based production scheduling and rescheduling in the presence of uncertainty. International Series in Operations Research \& Management Science, 152, 531-562.

Rosmaini, A., \& Shahrul, K. (2012). An overview of time-based and condition based maintenance in industrial application. International Journal of computers and Industrial Engineering, 63(1), 135-149.

Sabar, M., Montreuil, B., \& Frayret, J. M. (2009). A multi-agent-based approach for personnel scheduling in assembly centers. Engineering Applications of Artificial Intelligence, 22, 1080-1088.

Sawik, T. (2005). Integer programming approach to production scheduling for make-to-order manufacturing. Mathematical and Computer Modelling, 41(1), 99-118.

Seguy, A., Noyes, D., \& Clermont, P. (2010). Characterisation of collaborative decision making processes. International Journal of Computer Integrated Manufacturing, 23(11), 1046-1058.

Shakhlevich, N. V., \& Strusevich, V. A. (2005). Pre-emptive scheduling problems with controllable processing times. Journal of Scheduling, 8, 233-253.

Shen, W., Wang, L., \& Hao, Q. (2006). Agent-based distributed manufacturing process planning and scheduling: A state-of-the-art survey. IEEE Transactions on Systems, Man, and Cybernetics-Part C: Applications and Reviews, 36(4), 563-577.

Sim, S. H., \& Endrenyi, J. (1988). Optimal preventive maintenance with repair. IEEE Transactions on Reliability, 37(1), 92-96.

Si, X. S., Wang, W., Hu, C. H., \& Zhou, D. H. (2011). Remaining useful life estimation A review on the statistical data driven approaches. European Journal of Operational Research, 213, 1-14.

Sloan, T. W., \& Shanthikumar, J. G. (2000). Combined production and maintenance scheduling for a multiple product, single machine production system. Production and Operation Management, 9(4), 379-399.

Taillard, E. (1993). Benchmarks for basic scheduling problems. European Journal of Operational Research, 64(2), 278-285.

Tobon-Mejia, D., Medjaher, K., Zerhouni, N., \& Tripot, G. (2011). Hidden Markov models for failure diagnostic and prognostic. In Prognostics and system health management conference, PHM11. Shenzhen, China.

Vaurio, J. K. (1997). On time-dependent availability and maintenance optimization of standby units under various maintenance policies. Journal of Reliability Engineering and System Safety, 56, 79-89. 